\title{
Input Linkages and the Transmission of Shocks: Firm-Level Evidence from the 2011 Tōhoku Earthquake*
}

\author{
Christoph Boehm \\ Aaron Flaaen \\ Nitya Pandalai Nayar
}

September 11, 2014

\section{PRELIMINARY}

\begin{abstract}
Using novel firm-level microdata and leveraging a natural experiment, this paper provides causal evidence for the role of trade and multinational firms in the crosscountry transmission of shocks. Foreign multinational affiliates in the U.S. exhibit substantial intermediate input linkages with their source country. The scope for these linkages to generate cross-country spillovers in the domestic market depends on the elasticity of substitution with respect to other inputs. Using the 2011 Tōhoku earthquake as an exogenous shock, we estimate this elasticity for those firms most reliant on Japanese imported inputs: the U.S. affiliates of Japanese multinationals. These firms suffer large drops in U.S. output in the months following the shock, roughly proportional to the drop in imports and consistent with a Leontief relationship between imported and domestic inputs. Structural estimates of the production function for these firms yield disaggregated production elasticities that are similarly low. Our estimates suggest that global supply chains are sufficiently rigid to play an important role in the cross-country transmission of shocks.
\end{abstract}

JEL Codes: F10, F23, F44, E32

Keywords: Multinational Firms, International Business Cycles, Elasticity of Substitution

\footnotetext{
${ }^{*}$ University of Michigan, Department of Economics, 238 Lorch Hall, Ann Arbor, MI 48109-1220. chrisboe@umich.edu, aflaaen@umich.edu and npnayar@umich.edu. We would like to thank Andrei Levchenko, Kyle Handley, Matthew Shapiro, and Linda Tesar for valuable comments, suggestions, and support. We also thank Ruediger Bachmann, Javier Cravino, Chris House, Lutz Kilian, Illenin Kondo, Chris Kurz, Maggie Levenstein, Logan Lewis, William Lincoln, Andrew McCallum, Ryan Monarch, Justin Pierce and Jeff Smith for helpful conversations. This research has received research grants from the Michigan Institute for Teaching and Research in Economics (MITRE), for which we are very thankful. Support for this research at the Michigan RDC from NSF (ITR-0427889) is also gratefully acknowledged. Any opinions and conclusions expressed herein are those of the authors and do not necessarily represent the views of the U.S. Census Bureau. All results have been reviewed to ensure no confidential information is disclosed.
} 


\section{Introduction}

An important and encompassing topic in international economics in recent decades has been the spillover effects of trade and financial linkages across countries. The large expansions in trade and foreign direct investment (FDI) in the past twenty years have generated much discussion in whether they increase volatility (di Giovanni and Levchenko (2012)), increase comovement (Frankel and Rose (1998), Burstein, Kurz, and Tesar (2008)) or lead to less diversified production and specialization (Imbs (2004)). Identifying the micro-foundations underlying the role of these linkages in the increased co-dependence of national economies is a complicated task, however. Advanced economies are highly connected, and most variables influenced by any candidate mechanism are often correlated with other developments in the source and host countries. There is often little in the way of exogenous variation to isolate any particular mechanism from a host of confounding factors. Moreover, the requisite data to examine these issues at the necessary detail and disaggregation have been, until recently, unavailable.

This paper provides empirical evidence for the cross-country transmission of shocks via the rigid production linkages of multinational firms. The principal mechanism at work is not new: The idea of input-output linkages as a key channel through which shocks propagate through the economy dates back to at least Leontief (1936) or Hirschmann (1958). Two advances of this paper permit a new quantitative evaluation of the nature and magnitude of these linkages. First, we utilize a novel dataset consisting of restricted Census Bureau microdata with new links to international ownership structure to narrow in on particular firms and their underlying behavior. We develop a new methodology for isolating firm-level imports intended for further manufacture that focuses attention on the channel of vertical linkages. Second, we utilize the Tōhoku earthquake and tsunami as a natural experiment of a large and exogenous shock disrupting the production linkages emanating from Japan in the months following March 2011.

Affiliates of Japanese multinationals are the firms most directly impacted by this shock in the U.S. economy. These affiliates display near universally large imports of intermediates from their source country, a feature that is common to foreign multinational affiliates more generally (see Flaaen (2013b)). Substantial source-country imports do not by themselves point to these firms, or input-linkages more generally, as a key mechanism underlying the transmission of cross-country shocks. Disruptions to imported goods intended for final sale should have little effect on production 
or usage of factor inputs in the United States. Imported goods used as intermediate inputs in domestic production could affect the production process directly, but only if these inputs are not easily substitutable with inputs from alternative sources. In other words, the role of imported inputs in the transmission of shocks is governed by the elasticity of substitution with respect to domestic factors of production.

We estimate this elasticity using the relative magnitudes of high frequency input and output shipments in the months following the Tōhoku earthquake/tsunami. For Japanese multinational affiliates on average, we find this elasticity to be very low, close to zero. Reduced form estimates show that output shipments fall without a lag by a magnitude similar to the drop in imports. A structural model of the production function permits disaggregation of the production elasticities, and estimation at the level of the individual firm as well as across different subgroups of firms. The structural estimates are broadly in agreement with what applies to the average over the Japanese multinationals as a group. For Japanese multinationals, the elasticity across material inputs is 0.2 and the elasticity of substitution between material inputs and a capital/labor aggregate is 0.03. For non-Japanese firms using inputs from Japan, the elasticity of substitution across material inputs is, unsurprisingly, somewhat higher - at 0.6. We argue that a key source of this complementarity is the high share of intra-firm trade by multinationals.

This strong complementarity across material inputs implies that non-Japanese input use falls nearly proportionately, thereby propagating the shock to other upstream (and downstream) firms in both the U.S. economy and abroad. Many suppliers were thus indirectly exposed to the shock via linkages with Japanese affiliates that had i) high exposure to Japanese inputs and ii) a rigid production function with respect to other inputs. Network effects such as these can dramatically magnify the overall transmission of the shock (both across countries and within). And while such effects are commonly understood to exist, this paper provides unique empirical evidence of the central mechanisms at work.

The elasticity of substitution shows up in various forms in a wide span of models involving the exchange of goods across countries. As discussed by Backus, Kehoe, and Kydland (1994) and Heathcote and Perri (2002) among others, this parameter is critically important for the behavior of these models and their ability to match key patterns of the data. Prior estimates of this parameter were based on highly aggregated data that naturally suffered from concerns about endogeneity and 
issues of product composition 1 Reflecting the uncertainty of available estimates for the elasticity of substitution, it has become a common practice to demonstrate the behavior of these models along a wide array of parameter values.

It is well known that a low value for this parameter (broadly stated to include substitution between imported and domestic goods in final consumption or as intermediates in production) improves the fit of standard IRBC models along several important dimensions. In particular, the elasticity of substitution plays a role in two highly robust failings of these models: i) a terms of trade that is not nearly as variable as the data, and ii) the relative degree of output vs consumption comovement are switched relative to the data 2

To understand the relationship between the elasticity and comovement, it is helpful to recall that these models generate output comovement by inducing synchronization in factor supplies, a mechanism that by itself generally fails to produce the degree of comovement seen in the data. Complementarities among inputs together with heterogeneous input shocks will generate direct comovement in production, augmenting the output synchronization based on factor movements. Burstein, Kurz, and Tesar (2008) show that a low production elasticity of substitution between imported and domestic inputs reduces substitution following relative price movements, and thereby increases business cycle synchronization 3 It is also relatively straightforward to see how a lower elasticity increases volatility in the terms of trade. When two inputs are highly complementary, deviations from the steady state mix are associated with large changes in their relative prices. In the words of Heathcote and Perri (2002): "greater complementarity is associated with a larger return to relative scarcity." 4

The estimates in this paper have implications for the role of trade in firm-level and aggregate volatility. Other research has argued that firms can diversify risk arising from country specific shocks by importing (Caselli et al. (2014)) or that firms with complex production processes of several inputs are less volatile as each input matters less for production (Koren and Tenreyro

\footnotetext{
${ }^{1}$ For a very useful compendium of this research from this era, see Stern, Francis, and Schumacher (1976). More recently, work by Halpern, Koren, and Szeidl (2011) and Goldberg et al. (2010) demonstrate that materials inputs from foreign countries are imperfectly substitutable with domestic inputs for Hungary and India respectively.

${ }^{2}$ Due to the robust nature of these shortcomings, Backus, Kehoe, and Kydland (1995) refer to them as the "price anomaly" and "quantity anomaly" respectively.

${ }^{3}$ Although they do not estimate this parameter, the value they advocate $(0.05)$ is indeed close to our estimates.

${ }^{4}$ However, it should be noted that Backus, Kehoe, and Kydland (1995) indicate that, in their model, a lower elasticity of substitution improves the variability of prices only to make the variability of quantities much smaller than is observed in the data.
} 
(2013)). On the other hand, there is a well-established fact that complementarities and multi-stage processing can lead to the amplification of shocks as in Jones (2011) and Kremer (1993). We discuss the potential for measured amplification in our context in section 4.

This paper is also a contribution to the empirical evidence on the role of individual firms in aggregate fluctuations, emanating from the work of Gabaix (2011). Other related evidence comes from di Giovanni, Levchenko, and Méjean (2014), which uses French micro-data to demonstrate that firm-level shocks contribute as much to aggregate volatility as sectoral and macroeconomic shocks combined. The so-called granularity of the economy is very much evident in our exercise; though the number of Japanese multinationals is small, they comprise a very large share of total imports from Japan, and are arguably responsible for a quantitatively evident drop in U.S. industrial production following the Tōhoku earthquake (see Figure 3).

As is the case with most research based on an event-study, some care should be taken in extending the results to other situations. On the other hand, it should not be surprising that there are few substitutes for the specialized intra-firm trade undertaken between multinational affiliates $5^{5}$ Other research appears to confirm the role of multinationals in business cycle comovement: Using the regional dispersion of multinationals within France, Kleinert, Martin, and Toubal (2012) find a positive correlation with regional GDP comovement with the origin of multinationals in that region. They also find a high share of import shipments for these multinational affiliates.

The next section describes the empirical strategy and data sources used in this paper, and presents reduced form evidence in favor of a low production elasticity of imported inputs for Japanese multinational affiliates. In Section 3, we expand the scope of parameters we identify with a structural model of cross-country production linkages. We estimate the parameters of this model and discuss their implications. Section 4 discusses a number of checks and robustness exercises. The final section offers concluding thoughts.

\section{Empirical Strategy and Specification}

This section outlines the empirical approach of using an event-study framework surrounding the 2011 Tōhoku event to estimate the production elasticity of imported inputs. We discuss the relevant

\footnotetext{
${ }^{5}$ Such intra-firm trade accounts for a large majority of the trade of Japanese affiliates. More generally, the intra-firm share of imported intermediates for all foreign affiliates in the U.S. is 71 percent.
} 
details of this shock, document the aggregate effects, and then outline the empirical specification for the firm-level analysis.

\subsection{Background}

The Tōhoku earthquake and tsunami took place off the coast of Northeast Japan on March 11, 2011. It had a devastating impact on Japan, with estimates of almost twenty thousand dead or missing (Schnell and Weinstein (2012)) and substantial destruction of physical capital. The magnitude of the earthquake was recorded at 9.0 on the moment magnitude scale $\left(M_{\mathrm{w}}\right)$, making it the fourth largest earthquake event recorded in the modern era ${ }^{6}$ Most of the damage and casualties were a result of the subsequent tsunami that inundated entire towns and coastal fishing villages. The effects of the tsunami were especially devastating in the Iwate, Miyagi, and Fukushima prefectures. The Japanese Meteorological Agency published estimates of wave heights as high as 7-9m (23-29ft), while the Port and Airport Research Institute (PARI) cite estimates of the maximum landfall height of between $7.9 \mathrm{~m}$ and $13.3 \mathrm{~m}(26-44 \mathrm{ft})$.

Figure 1 shows the considerable impact of the Tōhoku event on the Japanese economy. Japanese manufacturing production fell by roughly 15 percentage points between February and March 2011, and did not return to trend levels until July. Much of the decline in economic activity resulted from significant power outages that persisted for months following damage to several power plants - most notably the Fukushima nuclear reactor 7 Further, at least six Japanese ports (among them the Hachinohe, Sendai, Ishinomaki and Onahama) sustained significant damage and were out of operation for more than a month, delaying shipments to both foreign and domestic locations. It should be noted, however, that the largest Japanese ports (Yokohama, Tokyo, Kobe) which account for the considerable majority of Japanese trade, re-opened only days after the event.

As expected, the economic impact of the event was reflected in international trade statistics, including exports to the United States. Figure 2 plots U.S. imports from Japan around the period of the Tōhoku event, with imports from the rest of the world for comparison. The large fall in

\footnotetext{
${ }^{6}$ Since 1900, the three earthquakes of greater recorded magnitude are: the 1960 Great Chilean earthquake (magnitude 9.5), the 1964 Good Friday earthquake in Prince William Sound, Alaska (magnitude 9.2); and the 2004 Sumatra-Andaman earthquake (magnitude 9.2)

${ }^{7}$ For precautionary reasons, all nuclear power plants were immediately shut down following the earthquake, and remained offline largely until 2014 or later. Because the electricity infrastructure exists on two separate grids (a $60 \mathrm{~Hz}$ to the south and west, and $50 \mathrm{~Hz}$ to the north and east), the reduction in power supply in Northeast Japan was not easily remedied, and power outages persisted for months.
} 
imports occurs during the month of April 2011, reflecting the several weeks of transit time for container vessels to cross the Pacific Ocean. The magnitude of this drop in imports is roughly similar to that of Japanese manufacturing production: a 20 percentage point drop from March to April, with a full recovery by July 2011.

More striking is the response of U.S. industrial production in the months following the event. Figure 3 demonstrates that there is indeed a drop in U.S. manufacturing production in the months following the Japanese earthquake. Although the magnitudes are obviously much smaller — roughly a one percentage point drop in total manufacturing and almost two percentage points in durable goods - the existence of a measurable effect is clear 8

Though tragic, the Tōhoku event provides a glimpse into the cross-country spillovers following an exogenous supply shock. This natural experiment features many characteristics that are advantageous for this type of study. It was large and hence measurable, unexpected, and directly affected only one country. The shock was also short-lived, which rules out immediate supplier restructuring and allows for an estimate of the elasticity for a given supply chain..$^{9}$ On the other hand, the short duration of the shock presents a challenge for measurement as it limits the available datasets with information at the required frequency. We utilize a novel firm-level dataset to uncover the mechanisms at work behind the transmission of this shock.

\section{$2.2 \quad$ Firm-Level Analysis}

Identification of the production elasticity of substitution will rely on the relative impacts on output and imported inputs following the shock. Consider the C.E.S. production function:

$$
x_{t}=\left[(1-\mu)^{\frac{1}{\psi}}\left[F_{D}(\cdot)\right]^{\frac{\psi-1}{\psi}}+\mu^{\frac{1}{\psi}}\left[M_{t}\right]^{\frac{\psi-1}{\psi}}\right]^{\frac{\psi}{\psi-1}},
$$

where output consists of combining a domestic bundle of inputs $F_{D}(\cdot)$, with a foreign imported input $M$. The parameter $\mu$ reflects the relative weight on the input $M$ in production, conditional on prices and a given elasticity value 10 Our approach in this section will be to estimate the

\footnotetext{
${ }^{8}$ At the level of total U.S. GDP, both Deutsche Bank and Goldman Sachs revised 2nd quarter U.S. estimates down by 50 basis points explicitly due to the events in Japan.

${ }^{9}$ It also rules out large balance sheet effects that would make differential credit conditions an operative feature.

${ }^{10}$ Specifying the prices of the inputs $F_{D}(\cdot)$ and $M$ as $P_{F}$ and $P_{M}$ respectively, the firm's optimization problem yields the following: $\frac{\left(P_{M}\right)^{\psi} M^{*}}{\left(P_{M}\right)^{\psi} M^{*}+\left(P_{F}\right)^{\psi} F_{D}^{*}(\cdot)}=\mu$.
} 
parameter $\psi$ governing the degree of substitution between these inputs, using information on the output elasticity with respect to imported inputs $\left(\frac{d \ln x}{d \ln M}\right)$ in the months following the shock.

Although it is fairly intuitive that there exists a mapping between the output elasticity and the elasticity of substitution after a shock to one of the inputs, we formalize this relationship with the following result:

Result 1. Assuming i) constant relative input prices, ii) an aggregate import bundle $M$ that reflects an optimal mix of subcomponents, and iii) $M$ is (weakly) scarce, then $\frac{d \ln x}{d \ln M}$ is a monotone function of the parameter $\psi$.

Proof. See appendix A for details.

Moreover, it is straightforward to show that $\lim _{\psi \rightarrow 0^{+}} \frac{d \ln x}{d l n M}=1$, which indicates that a onefor-one drop in output following a drop in imported inputs implies a Leontief $(\psi=0)$ production function. We discuss the effects of relaxing the assumptions underlying this fact in later sections.

\subsubsection{Data}

Several restricted-use Census Bureau datasets form the core of our firm-level analysis. The Longitudinal Business Database (LBD) collects the employment, payroll, and major industry of all establishments operating in the United States, and is maintained and updated as described by Jarmin and Miranda (2002). Longitudinal linkages allow the researcher to follow the establishment over time, and the annual Company Organization Survey (COS) provides a mapping from establishments to firms 11

An important component comes from the Longitudinal Foreign Trade Transactions Database (LFTTD), which links individual trade transactions to firms operating in the United States. Assembled by a collaboration between the U.S. Census Bureau and the U.S. Customs Bureau, the LFTTD contains information on destination (or source) country, quantity and value shipped, the transport mode, and other details from point-of-trade administrative documents. Importantly for this study, the trade transactions in the LFTTD includes import clearance and export declaration at a daily frequency, which is easily aggregated to monthly-level trade flows. A number of important papers have utilized this resource, such as Bernard et al. (2007) and Bernard, Jensen, and Schott (2006).

\footnotetext{
${ }^{11}$ All of the analysis in this paper will be at the firm-level.
} 
We utilize two novel extensions to this set of Census data products. First, a new link between a set of international corporate directories and the Business Register (BR) of the Census Bureau provides information on the international affiliates of firms operating in the United States. These directories contain firm-level information on cross-country ownership linkages, and are a critical resource for identifying the characteristics of U.S. firms affected by the Tohoku event. For information on these directories and the linking procedure used, please see Flaaen (2013b) and appendix B.1. The second novel data resource is a system to classify firm-level import transactions based on the expected use of the products. Although intermediate input trade represents as much as two-thirds of total trade (see Johnson and Noguera (2012)), the LFTTD does not classify a trade transaction based on its intended use. To remedy this limitation, we use information on the products produced by U.S. establishments in a given industry to identify the set of products intended for final sale for that industry ${ }^{12}$ The remaining products are presumably used by establishments in that industry either as intermediate inputs or as capital investment. Details on this classification procedure are available in Appendix B.2. In the aggregate, this firm-level classification procedure yields estimates of the intermediate share of trade that are consistent with prior estimates: 64 percent of manufacturing imports are classified as "intermediates" in 2007.

Finally, we utilize geographic information on the severity of the earthquake/tsunami that is compiled by the U.S. Geological Survey (USGS). By geocoding the Japanese addresses of firms with U.S. operations, we construct an earthquake intensity measure for each Japanese affiliate location. We then apply such information to the U.S. operations as a way to further measure the sample of firms plausibly affected by the shock. Please see Appendix B.3.2 for details. Figure 4 shows the geographic distribution of one such USGS measure - the modified mercalli index (MMI) - along with the geocoded affiliate locations.

The ideal dataset to evaluate the transmission of the Tōhoku event on U.S. firms would consist of high frequency information on production, material inputs, and trade, separated out by geographic and ownership criteria. Unfortunately, Census data on production and material inputs at the firmlevel is somewhat limited. The Annual Survey of Manufacturers (ASM) contains such information, but at an annual frequency and only for a subset of manufacturing firms. On the other hand, firm-level trade information is available at nearly a daily frequency, and covers the universe of

\footnotetext{
${ }^{12}$ Note that products intended for final sale for a given industry may still be used as intermediates for other firms in a different industry. Alternatively, such "final goods" can be sold directly to consumers for ultimate consumption.
} 
firms engaged in exporting/importing. For the purposes of characterizing the shock to firm-level imports of intermediate goods, the LFTTD (and supplements identified above) is ideal. There remain significant gaps in information on a firm's domestic input usage, a limitation we discuss in subsequent sections.

High-frequency information on firms' U.S. production is also a considerable challenge. Once again, traditional sources of this information are limited to annual frequencies and for select samples of manufacturing firms. Thus, recognizing the key advantage of longitudinal frequency which the LFTTD affords, we use a proxy proportional to a firm's U.S. production — namely the firm's exports of goods to North America (Canada and Mexico). The advantage of this approach is the ability to capture the flow of goods at a specific point in time. Moreover, there are few, if any, barriers to North American trade, and transport time is relatively short. Finally, as documented in Flaaen (2013b), exporting is a common feature of these firms, of which exports to North America is by far the largest component. The disadvantage of employing this approach is that it conditions on a positive trading relationship between firms in the U.S. and Canada/Mexico. The underlying assumption is that all firms export a fixed fraction of their U.S. output to neighboring countries. We will assess the use of this measure as a proxy in section $4.2 .1{ }^{13}$

\subsubsection{Spillovers by Firm Characteristics: Ownership vs Exposure}

This section narrows in on the firms that served as the primary carriers of the Tōhoku shock to the United States. A natural measure to evaluate potential carriers would be their degree of reliance on Japanese imported inputs. This is best expressed as the cost share of inputs from Japan, and can be constructed in a Census year by taking the Japanese imported inputs and dividing by all other inputs (which includes production worker wages and salaries, the cost of materials, and the cost of new machinery expenditures). Exposure to Japanese imported inputs is heavily concentrated among Japanese affiliates. In the year 2007, which is the closest available Census year, this cost share was nearly $22 \%$ on average for Japanese affiliates (see Table 3), compared to just $1 \%$ for other firms. A density estimate of each firm group across such an exposure measure indicates little overlap: few Japanese affiliates have low exposure to Japanese inputs, and few non-Japanese firms

\footnotetext{
${ }^{13}$ Another consideration with the use of this proxy is whether it more accurately reflects production or sales, as the two are distinct in the presence of output inventories. In our case, this depends on whether the inventories are held in the U.S. or Canada/Mexico. Without further evidence, we interpret the proxy to be capturing some mix between production and sales. The structural estimation in section 3 will allow for such a mix.
} 
have substantial exposure(see Figure 5 ) 14

To separate out the effects of input exposure to Japan from features such as multinational ownership, we construct a simple linear probability model of a disruption in Japanese inputs and U.S. output. The baseline model will be:

$$
X_{i k}^{D}=\alpha+\beta_{1} \mathrm{JPN}_{i k}+\beta_{2} \text { Exposed }_{i k}+\beta_{3} M M I_{i k}+\beta_{4} \text { Port }_{i k}+\gamma_{k}+\varepsilon_{i k}
$$

where the dependent variable $\left(X_{i k}^{D}\right)$ is an indicator equal to one if the N.A. exports of firm $i$ in industry $k$ are on average $20 \%$ below trend during the five months following the Tōhoku event. The independent variables are also indicators: $\mathrm{JPN}_{\mathrm{ik}}$, for affiliates of Japanese multinationals; Exposed $_{i k}$, for firms with an exposure to Japanese inputs above $0.05 ; M M I_{i k}$ for firms with an elevated MMI value pertaining to their average Japanese manufacturing locations; and Port ${ }_{i k}$ for firms that typically rely on imports via ports damaged by the tsunami 15 The $\gamma_{k}$ term allows for industry-specific intercepts. To evaluate the determinants of an input disruption from Japan, we replace the dependent variable with $J_{i k}^{D}$, an indicator for a drop in Japanese imported inputs of $20 \%$ relative to trend 16

Panel A of Table 1 evaluates firm characteristics predicting a drop in U.S. output $\left(X_{i k}^{D}\right)$, as measured by our proxy. The columns (1)-(4) show the results from different specifications with various combinations of the covariates in equation (2). Both Japanese ownership and high exposure to Japanese inputs significantly increase the probability of a output disruption, as expected. In columns (3) and (4), we demonstrate that Japanese ownership is substantially more indicative of an output decline than high input exposure alone. In Panel B, we replace the dependent variable with the binary measure of a drop in Japanese intermediate inputs $\left(J_{i}^{D}\right)$. The results from these regressions indicate, somewhat unsurprisingly, that high exposure to Japanese imports are highly predictive of a subsequent disruption following the Tōhoku event. Apart from their exposure to imports from Japan, the Japanese affiliates are no more likely to suffer a disruption to these imports (see column 8) ${ }^{17}$ The results in Panel A of Table 1, along with the graphical evidence from Figure

\footnotetext{
${ }^{14}$ The exposure measure used in Figure 5 is from 2010 and does not include cost of domestic material usage.

${ }^{15}$ Specifically, the $M M I_{i k}=1$ if the average Japanese manufacturing establishment corresponding to a U.S. firm is above the median (roughly an MMI of 5.2) of all firms with Japanese manufacturing locations. The affected ports are: Onahama, Hitachi, Kashima, Haramachi, Shiogama, Sendai, Shimizu, Ishinomaki, Hashinohe, Miya Ko, Kamaishi, Ofunato, and Kessennuma.

${ }^{16}$ We use the same sample of firms as in section 2.2 .3

${ }^{17}$ The sum of the coefficients on Japan and JPN*Exp is -0.16 , and not significant.
} 
5. point to a unique feature of the production function of Japanese affiliates: namely a low elasticity of substitution with respect to other inputs that yields direct pass-through of Japanese shocks to the U.S. economy. For this reason, we focus our subsequent analysis on the group of Japanese multinational affiliates.

\subsubsection{Reduced Form Estimates}

The analysis proceeds with an event study around the time of the Tōhoku event. We implement a dynamic treatment effects specification in which a firm is defined as being treated if it is owned by a Japanese parent company. The effect on these firms can be inferred from the differential impact of the variable of interest relative to a control group, which soaks up common seasonal patterns and other demand-driven factors in the U.S. market. While there are a number of competing methodologies for this type of estimation, we use normalized propensity score re-weighting due to the relatively favorable finite-sample properties as discussed in Busso, DiNardo, and McCrary (2014), as well as for its transparent intuition. Consistent estimation of the average treatment effect on the treated requires the assumption of conditional independence: the treatment/control allocation is independent of potential outcomes conditional on a set of variables. As the average Japanese firm differs considerably from other firms in the data, we use other multinational firms - both US and non-Japanese foreign- as our baseline control group prior to reweighting. Using this control group also helps mitigate potential concerns about the impact of the record linking procedure on sample selection. To compute the propensity scores for reweighting, we control for size and industry, which ensures the control group has a similar industrial composition and size distribution as our sample 18 Table 4 reports some summary values for the sample, including statistics on the balancing procedure using the normalized propensity score.

To isolate the total magnitude of the shock for a representative Japanese multinational, we look at the total imports of intermediate products for these firms 4 As is clear from Table 4 . the share of imported inputs coming from Japan - $70 \%$ of the total for Japanese firms vs $2 \%$ for non-Japanese multinationals - is the critical feature driving the identification. Let $V_{i, t}^{M}$ be the value of intermediate imports of firm $i$ in month $t$, after removing a firm-specific linear trend through

\footnotetext{
${ }^{18}$ Using the predicted values $(p)$ from the first stage regression, the inverse probability weights are $\frac{1}{1-p}$ for the control group and $\frac{1}{p}$ for the treated group. To normalize the weights such that the treated firms have weights equal to one, we then multiply each set of weights by $p$.

${ }^{19}$ We consider Japanese and non-Japanese intermediate imports separately in section 3
} 
March 2011. We fit the following regression:

$$
V_{i, t}^{M}=\alpha_{i}+\sum_{p=-4}^{9} \gamma_{p} E_{p}+\sum_{p=-4}^{9} \beta_{p} E_{p} \mathrm{JPN}_{i, p}+u_{i, t}
$$

where $\alpha_{i}$ are firm fixed-effects, $\gamma_{p}$ are monthly fixed effects (with the indicator variables $E_{p}$ corresponding to the calendar-months surrounding the event), and $u_{i, t}$ is an error term ${ }^{20}$

The $\beta_{p}$ coefficients are of primary interest. As before, the $\mathrm{JPN}_{i, t}$ is an indicator variable equal to one if the firm is owned by a Japanese parent company. Interacting these indicator variables with each month of the panel allows for a time-varying effect of Japanese ownership on a firm's overall intermediate input imports, particularly during and after the Tōhoku event. The $\beta_{p}$ coefficients will estimate the differential effect of the Tōhoku event on Japanese multinational affiliates in the U.S., compared to the control group of non-Japanese firms. To evaluate the differential impact on production for Japanese firms, we simply replace the dependent variable in equation (3) with the firm's North American exports, denoted $V_{i, t}^{N A}$.

It is important to highlight that the specification in (3) is in levels. There are several reasons for doing so, as opposed to using log differences or growth rates. First, allowing for the presence of zeros is important when the data are at a monthly frequency, particularly given the magnitude of the shock to imports for Japanese firms. The second reason is more conceptual. We are interested in calculating the mean effect of the Tōhoku event on some notion of a representative Japanese firm, rather than the effect on the mean Japanese firm. In a world of heterogeneous firms these effects are distinct. The former notion is captured with the levels specification that accounts for the absolute changes relative to a group-specific baseline ${ }^{21}$ In section 3 , we evaluate this framework with the results one would obtain when estimating the effect on a firm-by-firm basis.

In addition to the Conditional Independence Assumption highlighted earlier, the $\beta_{p}$ coefficients are valid estimates of the mean effect for Japanese affiliates only in so far as the control group is not itself impacted by the shock. This Stable Unit Treatment Value Assumption (SUTVA) implies that general equilibrium effects or peer effects (i.e. strategic interaction) do not meaningfully effect the estimates. The share of imported inputs from Japan is low for the control group, and thus the shock is unlikely to have a measurable effect on imported inputs as a whole. We discuss strategic

\footnotetext{
${ }^{20}$ The baseline sample will consist of January 2009 to December 2011 . We denote March 2011 as $\mathrm{t}=0$.

${ }^{21}$ See Appendix C.1 for more discussion, as well as results obtained using other specifications.
} 
interaction in section 4.2.4.

\subsubsection{Results: Total Manufacturing Sector}

The top panel of Figure 6 plots the $\beta_{p}$ coefficients from equation (3) for the months surrounding the Tōhoku event. Relative to the control group, there is a large drop in total intermediate input imports by Japanese firms in the months following the earthquake. The drop in intermediate inputs bottoms out at 4 million USD in $t=3$ (June 2011) and the point estimates do not return back to the pre-shock trend until month $t=7$ (October 2011).

More interesting are the results from panel B of Figure 6, which looks for evidence for the production/sales impact of this shock on Japanese firms via their North American exports. The differential time-path of N.A. exports also exhibits a substantial drop following the Tōhoku event, hitting a trough of 2 million USD below baseline in $t=2$ (May 2011). The standard errors, which are clustered at the firm-level, are themselves interesting. As made clear via the 95-percent confidence bands on the point estimates of Figure 6, the standard errors increase dramatically in the months following the shock, a feature we interpret to reflect heterogeneous incidence and timing of the shocks (as well as the recoveries) for the Japanese multinationals.

To gain a sense of the average percentage drops of these two data series for Japanese multinationals as a group, we take the two plots of the differential dollar amounts from Figure 6 and divide by the average pre-shock level for these firms (see Table 4). The results, plotted jointly in Figure 7 , show the fraction below pre-shock trend levels for these firms, on average. There is a remarkable correlation between these two series - whereby there is essentially a one-for-one drop in output for a given drop in intermediate imports. Using the mapping from Result 1, these reduced form results suggest a production function that is essentially Leontief in the imported input. On the other hand, one should be cautious in reaching this conclusion while abstracting away from many other features of firm behavior.

\section{$3 \quad$ Firm-Level Estimation of Cross Country Input Linkages}

The relative movements of imported inputs and output of Japanese multinational firms point to little substitutability of Japanese intermediate inputs. In this section we expand our analysis by structurally estimating the production function of firms affected by the Tōhoku shock. We do this 
for three reasons. First, it is reassuring to find similar elasticity estimates as those implied by our reduced-form results when imposing a production structure that is conventional in the literature. Second, by imposing additional structure, we are able to distinguish two elasticities: one between Japanese material inputs and other material inputs, and another between an aggregate bundle of material inputs and domestic capital and labor. Finally, by using an estimation procedure not relying on a control group we can obtain separate estimates for Japanese and non-Japanese firms. The results corroborate the claim that the supply chains of Japanese and non-Japanese exhibit different degrees of rigidity.

The estimation procedure will utilize information from two distinct periods: the six months preceding and the six months following the March 11 event. The pre-period, which we denote by $\tau-1$, yields information on the production function of the firm under profit-maximizing conditions. In the post-period, denoted $\tau$, we do not impose that the firm is optimizing over its input use, due to the fact that shipments from Japan are to some extent beyond the control of the firm.

\subsection{Framework}

We assume that the firm's technology in any period $t$ is given by the nested CES aggregate

$$
x_{i, t}=\phi_{i}\left[\mu_{i}^{\frac{1}{\zeta}}\left(K_{i, t}^{\alpha} L_{i, t}^{1-\alpha}\right)^{\frac{\zeta-1}{\zeta}}+\left(1-\mu_{i}\right)^{\frac{1}{\zeta}} M_{i, t}^{\frac{\zeta-1}{\zeta}}\right]^{\frac{\zeta}{\zeta-1}},
$$

where

$$
M_{i, t}=\left(\nu_{i}^{\frac{1}{\omega}}\left(m_{i, t}^{-J}\right)^{\frac{\omega-1}{\omega}}+\left(1-\nu_{i}\right)^{\frac{1}{\omega}}\left(m_{i, t}^{J}\right)^{\frac{\omega-1}{\omega}}\right)^{\frac{\omega}{\omega-1}} .
$$

In this formulation $x_{i, t}, K_{i, t}$, and $L_{i, t}$ denote the firm's output, capital, and labor, and $M_{i, t}$ is an aggregate of intermediate inputs. The term $M_{i, t}$ itself consists of materials sourced from Japan $\left(m_{i, t}^{J}\right)$ and materials sourced from all places other than Japan $\left(m_{i, t}^{-J}\right)$, including domestic materials. We are interested in estimating $\omega$ and $\zeta$, which parameterize the substitutability between Japanese and non-Japanese materials and that between the capital-labor aggregate and the aggregate of intermediate inputs. The $\mu_{i}$ and $\nu_{i}$ are firm-specific weights and $\phi_{i}$ parameterizes the firm's productivity which we assume is constant over the short time horizon we consider. Further, we assume 
that the firm is monopolistically competitive and faces a CES demand function

$$
p_{i, t}^{x}=\left(\frac{Y_{i, t}}{x_{i, t}}\right)^{\frac{1}{\varepsilon}} \text {. }
$$

As usual, $Y_{i, t}$ is the bundle used or consumed downstream and serves as a demand shifter beyond the control of the firm.

\subsubsection{Pre-Tsunami period}

Let $\tau$ denote the six month time period starting in April 2011 and $\tau-1$ the six month before the Tōhoku event (September 2010 to February 2011). We exclude the month of March 2011. In period $\tau-1$ the firm operates in a standard environment, choosing capital, labor, and materials so as to maximize

$$
p_{i, \tau-1}^{x} x_{i, \tau-1}-w_{\tau-1} L_{i, \tau-1}-R_{\tau-1} K_{i, \tau-1}-p_{i, \tau-1}^{-J} m_{i, \tau-1}^{-J}-p_{i, \tau-1}^{J} m_{i, \tau-1}^{J}
$$

subject to (4), (5), and (6). The firm takes all factor prices as given ${ }^{22}$

It is straightforward to show that that this optimization problem implies

$$
\begin{aligned}
K_{i, \tau-1} & =\frac{\alpha}{1-\alpha} \frac{w_{\tau-1} L_{i, \tau-1}}{R_{\tau-1}}, \\
\nu_{i} & =\frac{\left(p_{i, \tau-1}^{-J}\right)^{\omega} m_{i, \tau-1}^{-J}}{\left(p_{i, \tau-1}^{J}\right)^{\omega} m_{i, \tau-1}^{J}+\left(p_{i, \tau-1}^{-J}\right)^{\omega} m_{i, \tau-1}^{-J}}, \\
\mu_{i} & =\frac{\left(\left(\frac{R_{\tau-1}}{\alpha}\right)^{\alpha}\left(\frac{w_{\tau-1}}{1-\alpha}\right)^{1-\alpha}\right)^{\zeta} K_{i, \tau-1}^{\alpha} L_{i, \tau-1}^{1-\alpha}}{\left(P_{i, \tau-1}^{M}\right)^{\zeta} M_{i, \tau-1}+\left(\left(\frac{R_{\tau-1}}{\alpha}\right)^{\alpha}\left(\frac{w_{\tau-1}}{1-\alpha}\right)^{1-\alpha}\right)^{\zeta} K_{i, \tau-1}^{\alpha} L_{i, \tau-1}^{1-\alpha}},
\end{aligned}
$$

where

$$
P_{i, \tau-1}^{M}=\left[\nu_{i}\left(p_{i, \tau-1}^{-J}\right)^{1-\omega}+\left(1-\nu_{i}\right)\left(p_{i, \tau-1}^{J}\right)^{1-\omega}\right]^{\frac{1}{1-\omega}} .
$$

We will use these relationships in the structural estimation that follows below.

\footnotetext{
${ }^{22}$ Material prices $p_{i, \tau-1}^{J}$ and $p_{i, \tau-1}^{-J}$ are firm-specific to indicate that different firms use different materials.
} 


\subsubsection{Post-Tsunami period}

At the beginning of period $\tau$ many firms' production processes in Japan are disrupted. Obtaining the desired amount of shipments of materials from Japan may either be prohibitively expensive or outright impossible. Modeling firms' behavior in this environment therefore requires modifications to the previous setup. One possibility is to assume that the quantity of materials that firms obtain from Japan are exogenous and that firms freely choose non-Japanese materials, capital and labor. This option is unattractive for two reasons. First, due to existing contracts it is unlikely that a firm is able to adjust the quantities of non-Japanese materials, capital, and labor without costs in such a short time frame. The obvious remedy is to add adjustment costs to the model. Although straightforward, this avenue would require us to estimate additional parameters. Second, and more

importantly, the materials sourced from Japan $\left(m_{i, t}^{J}\right)$ may not be exogenous for every firm. Some firms' suppliers in Japan may be unaffected by the earthquake and tsunami so that materials can be shipped as desired. Hence, using this approach would require us to distinguish between firms whose supply chains are disrupted and those whose are not. That is, we would have to classify firms based on an endogenous outcome.

For these reasons we prefer an alternative approach, namely to estimate the production function without specifying the full optimization problem: In period $\tau$, firms operate the same technologies given by 4 and 5 . We only assume that no firm adjusts its capital stock so that $K_{i, \tau}=K_{i, \tau-1}$. Given the short-lived nature of the shock we believe that this approximation is fairly accurate. Beyond this no assumptions are made on the firms' optimization problems which likely involve intertemporal choices subject to a number of complicating constraints.

\subsection{Estimation}

Recall that we used North American exports as a proxy proportional to the value of shipments $p_{i, t}^{x} x_{i, t}$ in earlier sections. We continue here in the same spirit. Let $V_{i, t}^{N A}$ be the value of North American exports at time $t$ and define

$$
\kappa_{i}=\frac{V_{i, \tau-1}^{N A}}{p_{i, \tau-1}^{x} x_{i, \tau-1}} .
$$


In words, $\kappa_{i}$ is the fraction of firm $i$ 's shipments exported to Canada and Mexico in the six months preceding the tsunami. We next make two assumptions that allow us to construct an estimation equation. First, we assume that a relationship analogous to 10 continues to hold in period $\tau$, except for a log-additive error $u_{i, \tau}$. That is,

$$
\ln V_{i, \tau}^{N A}=\ln \kappa_{i} p_{i, \tau}^{x} x_{i, \tau}+u_{i, \tau}
$$

The second assumption is that $\mathbb{E}\left[u_{i, \tau} \mid X_{i}\right]=0$ where $X_{i}$ is a vector of all right-hand-side variables. Setting the conditional mean of $u_{i, \tau}$ to zero is a standard exogeneity assumption requiring that, loosely speaking, the error is uncorrelated with all right-hand-side variables. It rules out, for example, that in response to a fall in Japanese intermediate imports firms export a fraction of their shipments to Canada and Mexico that systematically differs from $\kappa_{i}$. Evidence we provide in section 4.2.1 indicates this to be a reasonable assumption.

Using equation (4) we can rewrite (11) as

$$
\ln \left(V_{i, \tau}^{N A}\right)=\ln \left(\kappa_{i} \phi_{i}\right)+\ln \left(\left[\mu_{i}^{\frac{1}{\zeta}}\left(p_{i, \tau}^{x} K_{i, \tau}^{\alpha} L_{i, \tau}^{1-\alpha}\right)^{\frac{\zeta-1}{\zeta}}+\left(1-\mu_{i}\right)^{\frac{1}{\zeta}}\left(p_{i, \tau}^{x}\right)^{\frac{\zeta-1}{\zeta}}\left(M_{i, \tau}\right)^{\frac{\zeta-1}{\zeta}}\right]^{\frac{\zeta}{\zeta-1}}\right)+u_{i, \tau} .
$$

Under standard assumptions, this equation can be consistently estimated using, e.g., nonlinear least squares. Values for $\nu_{i}$ and $\mu_{i}$ are obtained from equations (8) and (9) ${ }^{23}$ Using (10), the intercept can be constructed from the previous period

$$
\kappa_{i} \phi_{i}=\frac{V_{i, \tau-1}^{N A}}{\left[\mu_{i}^{\frac{1}{\zeta}}\left(p_{i, \tau-1}^{x} K_{i, \tau-1}^{\alpha} L_{i, \tau-1}^{1-\alpha}\right)^{\frac{\zeta-1}{\zeta}}+\left(1-\mu_{i}\right)^{\frac{1}{\zeta}}\left(p_{i, \tau-1}^{x}\right)^{\frac{\zeta-1}{\zeta}}\left(M_{i, \tau-1}\right)^{\frac{\zeta-1}{\zeta}}\right]^{\frac{\zeta}{\zeta-1}}} .
$$

Notice that $\kappa_{i}$ and $\phi_{i}$ are not separately identified. We calibrate $\alpha=1 / 3$ so that the remaining parameters to estimate are $\zeta$ and $\omega$.

Why do we restrict the sample to the year surrounding the Tōhoku event? To understand this, recall that the principle difficulty of estimating production functions lies in unobserved inputs and productivity. Since both are unobserved by the econometrician, they are absorbed into the error term. However, because they are known to the firm, other input choices depend on them. Hence, right-hand-side variables and the error term will generally be correlated, rendering estimates

\footnotetext{
${ }^{23}$ After constructing $\mu_{i}$ according to equation 9 we average by industry to reduce the level of noise.
} 
inconsistent 24

By restricting the sample period to a single year, the assumption of constant firm productivity seems appropriate. If productivity is constant, it cannot be correlated with the error term, thereby ruling out one of the concerns 25 The fact that the Tōhoku event was an unexpected shock negates much of the concern about endogeneity arising from unobserved inputs. To see why, consider the case when the firm anticipates a supply chain disruption in a future period. Firm adjustment of unobserved inputs in expectation of this shock will impact input choices - leading to an endogeneity issue where inputs are correlated with the shock. Put simply, the unexpected nature of the Tohoku event works towards equalizing the information sets between the econometrician and the firm because factor choices are made before the shock is observed 26

Before turning to the data we briefly discuss the intuition of parameter identification. Unlike other approaches to estimating elasticities of substitution (e.g. Feenstra et al. (2014)), our method does not rely on the response of relative values to a change in relative prices ${ }^{27}$ In fact, in an econometric sense, our approach treats all inputs as independent variables.

A simple example illuminates how the parameters are identified. Consider the production function (4) and compare two hypothetical firms with identical values for $\phi_{i}, \mu_{i}, \nu_{i}$ and the capitallabor aggregate. The only dimensions in which the two firms differ after the shock is deliveries of the materials aggregate $M_{i, t}$ and output shipments $x_{i, t}$. Suppose for concreteness that in period $\tau$ firm A uses half the amount of material inputs as firm B. If firm A's output is also half of firm B's output in period $\tau$, then the elasticity $\zeta$ most consistent with this observation is zero. If A's output differential is less than the material differential, the elasticity is larger. Similar reasoning applies for the identification of $\omega$ based on relative movements in Japanese materials, non-Japanese materials, and output. In summary, we estimate the production functions directly off of crosssectional variation in output and input movements across the firms in the sample. Our tests on simulated data suggest that the procedure works well.

\footnotetext{
${ }^{24}$ This problem is discussed in greater detail in, for example, Ackerberg, Caves, and Frazer (2006).

${ }^{25}$ Of course, the size and exogeneity of the shock also helps with this concern: any idiosyncratic productivity movements during this time are surely subsumed by the earthquake/tsunami.

${ }^{26}$ An unobserved input that could remain operative in our case is that of factor utilization. Since the scope for substantial adjustment along this dimension seems quite limited, we remain confident that our estimates would be robust to the inclusion of this missing ingredient.

${ }^{27}$ Given that we observe little systematic variation in prices (see section 4.2.4), we believe that our approach is more appropriate in this setting.
} 


\subsection{Connecting Model and Data}

Estimation of the model requires data on employment, Japanese, and non-Japanese material inputs as well as on exports to North America and output prices for periods $\tau-1$ and $\tau$. Since data on firm-specific capital stocks is hard to obtain and likely noisy, we use equation (7) to construct it from firm payroll and a semi-annual rental rate of 7 percent for period $\tau-128$ Recall that the capital stock is not adjusted over this time horizon so that $K_{i, \tau}=K_{i, \tau-1}$. The parameter $\alpha$ is calibrated to $1 / 3$.

Quarterly employment information comes from the Business Register, which we adjust to reflect the average value over the 6 month periods we study ${ }^{29}$ As discussed in earlier sections, the LFTTD contains firm-level data of Japanese imports and North American exports. For nonJapanese material inputs, we would ideally combine the non-Japanese imported materials with information on domestic material usage for these firms. As information on domestic material inputs is not available in Census data at this frequency, we utilize information on the total material expenditures from the Census of Manufacturers (CM) to construct a firm-level scaling factor to gross up non-Japanese intermediate imports. Put differently, we impute non-Japanese material inputs from non-Japanese input imports. For each firm, we construct the scaling factor as

$$
\frac{P_{i}^{M} M_{i}-p_{i}^{J} m_{i}^{J}}{p_{i}^{-J} m_{i}^{-J}}
$$

from the latest CM year. Because the closest available CM year is 2007 in our data, there is some concern of missing or outdated information for this factor. We mitigate this by using industryspecific means for missing values, and winsorizing large outliers at the 90th/10th percentiles.

Regarding information on prices, the LFTTD records the value and quantity of each trade transaction (at the HS10 level), and thus it is possible to construct the associated price, or "unitvalue" of each shipment directly ${ }^{30}$ Aggregating up these shipments into a firm-month observation is complicated, of course, by the differing quantity units. Lacking any better alternative, we simply average the transactions using the dollar value of each transaction as weights.

Finally, we restrict the sample of firms to those that have regular imports from Japan and

\footnotetext{
${ }^{28}$ The estimates are insensitive to alternative values of the rental rate.

${ }^{29}$ Specifically: $L_{t-1}=\frac{1}{6} E m p_{2010 Q 3}+\frac{1}{2} E m p_{2010 Q 4}+\frac{1}{3} E m p_{2011 Q 1}$ and $L_{t}=\frac{1}{2} E m p_{2011 Q 2}+\frac{1}{2} E m p_{2011 Q 3}$.

${ }^{30}$ Those transactions with missing or imputed quantity information are dropped. Future efforts will evaluate whether it is possible to recover the quantity values from prior transaction details.
} 
non-Japan over the periods we study, as well as regular North American exports 31 While this substantially limits the number of firms in each sample, the shares of trade represented by these firms in each category remains very high (see table 5).

We obtain standard errors using bootstrap methods, which also allow us to account for the uncertainty implied by the imputation of non-Japanese material inputs. We draw randomly with replacement from our set of firms to construct 5000 different bootstrap samples. For each of these samples, the non-Japanese materials share is imputed as described above before the estimation proceeds.

\subsection{Summary of Results}

The results of the estimation are shown in Table 5. The elasticity between material inputs for Japanese affiliates is 0.2 , while the elasticity between the aggregate material input and capital/labor is 0.03. Together, these estimates are indeed consistent with an informal estimate of the $(\psi)$ elasticity from section 2.2.4. The relative magnitudes are also intuitive: while Japanese imported inputs are strong complements with other material inputs - consistent with the high share of intra-firm transactions comprising this trade - there is even less scope for substitution between material inputs and domestic capital/labor.

The estimation procedure also allows us to estimate these elasticities for non-Japanese multinationals. While the estimates for the $\zeta$ elasticity are indeed very close, the elasticity estimate corresponding to material inputs for non-Japanese multinationals is considerably higher, at 0.6. The lower share of intra-firm imports from Japan for this group is consistent with the argument that this type of trade is the key source of non-substitutability in the short-run. We should note, however, that the estimates for both parameters are significantly lower than unity - a common assumption in the literature.

Other details from this estimation make intuitive sense. The weight on Japanese materials in the aggregate materials bundle is 0.17 for Japanese multinationals, and 0.04 for non-Japanese firms. The weight on domestic capital/labor is considerably lower for Japanese firms - 0.22 compared to 0.51 for non-Japanese firms - which could point to either i) a more assembly-oriented production or ii) a different industry mix.

\footnotetext{
${ }^{31}$ Specifically, we drop any firm that has more than 3 months of zeros for any of these values, over the period $t-1$ or the period $t$.
} 
Although the number of firms included in this estimation is small (105 Japanese affiliates and 304 non-Japanese multinationals), they account for a large share of economic activity in the United States. Looking at their combined share of total trade, these firms account for over $80 \%$ of Japanese intermediate imports, $68 \%$ of non-Japanese intermediate imports, and well over $50 \%$ of North American exports. Such high concentration of trade among relatively few firms is consistent with other studies using this data (see Bernard et al. (2007)).

\section{Discussion}

The structural estimates of the model are broadly in agreement with those from section 2.2.4. imported inputs are strong complements with other inputs in the production function. The rigidity of the production function for multinational firms is likely due to the substantial presence of intrafirm trade in what is presumably highly-specialized inputs. This result has a number of important implications for how we think about business cycle co-movement, firm volatility, and multinational firms more broadly.

\subsection{Implications}

The low value for $\omega$ indicates the presence of spillovers beyond the immediate effect from Japan. That is, imports from non-Japanese locations are lower as a result of the shock in Japan, and we would presume this applies to suppliers within the United States as well. Specifically, upstream suppliers (in countries other than Japan as well as within the U.S.) were affected indirectly due to the exposure of Japanese affiliates to the shock combined with the rigidity of their production with respect to those inputs. The presence of such spillovers combined with the large network of input linkages can indeed magnify the total effect of the transmission of the shock to the U.S. market. Such effects are also evident in a related paper, Carvalho, Nirei, and Sato (2014), which finds large spillovers in both upstream and downstream firms in Japan following the 2011 earthquake.

The rigid production networks of foreign-owned multinationals will have direct consequences on the destination (host) economy. Previous literature has hypothesized that input linkages could generate business-cycle comovement, but supportive empirical evidence has been difficult to find. This paper can be seen as a first step in establishing empirical evidence for a causal relationship between trade, multinational firms, and business cycle comovement. In a companion paper Boehm, Flaaen, 
and Pandalai Nayar (2014)), we evaluate the quantitative importance of such complementarities of imported inputs by multinational affiliates. When separately accounting for intermediate input trade by multinationals from traditional trade in final goods, the model separates the production elasticity of imported inputs with the traditional "Armington" elasticity used to bundle together international goods for consumption. The complementarities in import linkages by multinationals increases value-added comovement in the model by as much as 18 percentage points relative to a benchmark without such firms.

This model share similarities with several other existing models, particularly Burstein, Kurz, and Tesar (2008). A key advantage of Boehm, Flaaen, and Pandalai Nayar (2014), however, is a tight link to Census data for matching other features of multinationals and trade. Research in Johnson (2014) also looks at the role of vertical linkages on comovement, but applies greater inputoutput structure on the model. Such features will generate increases in value-added comovement in his model, the magnitude of which becomes significant only when the elasticity of substitution among inputs is sufficiently low. Other work also identifies multinationals as a key source of the transmission of shocks: a new paper by Cravino and Levchenko (2014) demonstrates that foreign multinational affiliates can account for about 10 percent of aggregate productivity shocks 32

Another branch of literature on the diversification of risk has studied whether firms using complex production structures with several intermediates could be less volatile (Koren and Tenreyro (2013)). Kurz and Senses (2013) establish that firms with substantial imports and exports have lower employment volatility than domestic firms in the medium to long term, which they attribute partly to the diversification of risk. 33 The key result in this paper points to a possibly overlooked fact: the extent of the benefits from diversification depends heavily on the substitutability of inputs. That is, a firm with a complex production structure spanning many inputs will likely experience an increase in volatility if each input is key to the production process and inputs are subject to heterogeneous shocks. Conceptually, an increase in the use of imported inputs should not be viewed necessarily as diversification. A fragmentation of production can lead to an increased supply chain risk that is an important counterweight to whatever efficiencies such complex input sourcing might afford, particularly when the production elasticities are low.

\footnotetext{
${ }^{32}$ Of course, shocks can be passed through to affiliates through other means as well. See Peek and Rosengren (1997) and Peek and Rosengren (2000) for the case of U.S. affiliates from Japan.

${ }^{35}$ An interesting result from Kurz and Senses $\sqrt{2013}$ is that firms that only import are actually more volatile than the domestic-only benchmark.
} 
In the estimation frameworks from sections 2.2.3 and 3, we consider the aggregate bundle of imported Japanese material intermediates, abstracting away from product-level detail. In reality, the firms in our dataset often import many distinct intermediate inputs from Japan. The structure of a CES production function implies that if each of these within-country inputs was non-substitutable with one another (a further, nested Leontief structure), the production impact of a disruption in the supply of just one input could be amplified relative to the value of that input ${ }^{34}$ We evaluate this possibility, and the influence it may have on the estimation of the other elasticity parameters, in section 4.2 .3 below.

The rigid production networks of multinational firms also influences our understanding of why firms segment production across country borders. In a related paper, Flaaen (2013b) shows that despite the presence of substantial and complex import linkages with the source country (consistent with a vertical framework of FDI), the motive for multinational production appears to be to serve the domestic market (consistent with the horizontal framework of FDI). The result could be called "horizontal FDI with production sharing." "35 The evidence for strong complementarities in this production sharing, however, presents a puzzle. Why does the firm replicate only select portions of the supply chain, considering the penalties for disruptions and mismatched inputs are so great? It is perhaps the case that the segments of the production chain that remain in the source country have a location-specific component that is not easily transferable when the firm moves production abroad ${ }^{36}$ Understanding the dynamics behind these sourcing decisions is an area in need of further research 37

Finally, the estimates from section 3 correspond to an average across the firms in each group (Japanese multinationals and non-Japanese firms), the results from section 2.2.4 correspond to the aggregated group of Japanese multinationals. Because the level of aggregation differs, it is important for the researcher to understand the appropriate model analogue when using these estimates for the calibration of theoretical models 38 For example, a researcher may decide that a group-level

\footnotetext{
${ }^{34}$ This point has been made in somewhat differing contexts, by Jones (2011) and Kremer (1993).

35 Ramondo, Rappoport, and Ruhl (2007) is another recent example arguing for a more nuanced interpretation of multinational production.

36 The model of knowledge sharing in Keller and Yeaple (2013) is one attempt to analyze the dynamics between such transfers being accomplished in embodied (intra-firm trade) or disembodied (direct communication) form. Alternatively, domestic content requirements may provide incentives to produce specified inputs in one location over another.

${ }^{37}$ For a recent example of how such investment and sourcing decisions can alter a country's comparative advantage over time, see Alviarez (2014).

${ }^{38} \mathrm{~A}$ recent paper by Imbs and Méjean (2011) argues that imposing homogeneity across sectors when estimating
} 
elasticity is the most appropriate for an aggregate DSGE model populated by a representative multinational firm, where the focus is on understanding aggregate features such as business cycle dynamics.

\subsection{Robustness and Extensions}

\subsubsection{Mis-measurement of Firm Production}

A natural concern with our analysis is the use of N.A. exports as a proxy for firm-level production. Perhaps it is the case that shipments abroad fall disproportionately more than domestic shipments following a shock to production. If this were the case, the N.A. exports would indeed be a poor proxy for production, and its usefulness in evaluating a production elasticity substantially compromised.

To evaluate this concern, we narrow our study to the automotive sector, which has data on production, sales, and inventory at a monthly frequency. Using the Ward's electronic databank, which reproduces the published series in the annual Automotive Yearbook, we obtain plant-level information on production, and model-line information on inventory, sales, and incentives 39 The baseline specification is the same as in equation (3), where the dependent variable is now $Q_{j i t}$ : production of plant $j$ of firm $i$ in month $t$. The Japanese multinational firms are, in this case, those automakers with plants located within North America but whose parent company is headquartered in Japan 40

Figure 8 shows the results. Relative to their U.S. counterparts, Japanese firms operating in the United States experienced a large drop in production following the Tōhoku event. The fall in production bottomed out in May of 2011 - two months after the event - at just over -6400 units a month 41 The point estimates return to a level near zero in September of 2011, implying that the shock affected production for nearly 6 months 42 We interpret these results to be largely supportive of the results obtained using the exports-based proxy for production. In fact, the percentage drops in the two series are remarkably similar: a trough of $52 \%$ at $t=2$ in the automotive data vs $53 \%$ at $t=2$ using the proxy. We conclude that, at least for this exercise, the proxy appears to be

consumption elasticities can be overly restrictive, creating a heterogeneity bias which can be quantitatively large.

${ }^{39}$ Appendix C.4 details further features of this data and explains how the sample was constructed.

${ }^{40}$ These firms are Honda, Mitsubishi, Nissan, Toyota, and Subaru.

${ }^{41}$ The average monthly plant-level production at these firms during December 2010 through February 2011 was about 12,200 units a month. This implies a $52 \%$ drop relative to before the event.

${ }^{42}$ We describe additional results on the behavior of inventories, sales, incentives, and production in Japan in an appendix. 
providing valuable information on a firm's U.S. production behavior 43

\subsubsection{Intermediate Input Inventories}

Inventories are another obvious feature that should influence the relationship between input shipments, production, and the elasticity of substitution. In particular, inventories of intermediate inputs allow the firm to absorb unforeseen shocks to input deliveries without an impact on the production process ${ }^{44}$ As it relates to the production elasticity, however, the presence of these inventories should serve to diminish or delay the production impact, thereby increasing the elasticity relative to what it would be without such inventories.

In fact, it is striking the extent to which we do not see any evidence for the role of intermediate input inventories in the production impacts of Figure 6 (Panel B) or Figure 8. The effect on production appears to be almost immediate, indicating that the stock of inventories of imported intermediates is low (less than one month's supply) for these firms.

We obtain a rough sense of the degree of inventory holdings from the Census of Manufacturers micro-data. Combining information on the beginning period stock of materials inventories with the annual usage of materials, we calculate the average monthly supply of inventories for each firm.45 Panel A of Table 3 calculates the production-weighted averages over a select set of firm groups 46 We see that on average, Japanese multinationals hold a little over 3-weeks supply of intermediate inputs as inventory. This is slightly less than non-multinational firms, a fact that aligns with the oft-cited "lean" production processes made famous by Japanese firms in previous decades. Though this data corresponds to the year 2007, there is little reason to believe these relative magnitudes have changed substantially over a period of a few years. For completeness, Panel A of Table 3 also

\footnotetext{
${ }^{43}$ In addition, one might be concerned that the N.A. exports series may be contaminated with Japanese imports whose country of ultimate destination is Canada/Mexico (a.k.a "in-transit shipments" - imports to Canada/Mexico via U.S.). These shipments should not be picked up in the reporting systems underlying the LFTTD. According to section 30.2(d)(1) of the U.S. Code of Federal Regulations, "In-transit shipments of goods from one foreign country to another where such goods do not enter the consumption channels of the United States are excluded from filing the Electronic Export Information (EEI)." Additionally, the Army Corps of Engineers has suspended the requirement to file the Form 7513, Shippers Export Declaration (SED) for In-transit Goods leaving the United States via vessel. Finally, the corroborating results from section 4.2.1 should also serve to allay such concerns.

${ }^{44}$ The existence of final good inventories, on the other hand, makes a distinction between the production and sales of a particular product. Here, the presence of final good inventories implies that the firm can continue to sell from existing inventory stocks even while production is temporarily affected.

${ }^{45}$ Unfortunately, the CM data does not report imported materials inventory separately.

${ }^{46}$ These numbers are broadly similar, though somewhat lower than other estimates in the literature. See Ramey (1989) for one example.
} 
reports the corresponding estimates for output inventories ${ }^{47}$

\subsubsection{Multi-Products and Sub-Optimal Mix}

As is clear in Figure 4, the Tōhoku event had a heterogeneous impact across Japan. As a result, one might wonder whether there is considerable dispersion in the impact on the products imported by a particular U.S. firm or Japanese affiliate. With product-level shocks, considering the effect on the aggregate import bundle amounts to assuming either 1) perfect substitutability among products, or 2) that the firm maintains an optimal within-country product mix at all times.

To be concrete, it may be more accurate to view the $M_{t}$ in equation (1) as a further C.E.S. function of multiple products. Thus, we can define the proper measurement of this variable as

$$
V_{i, t}^{M}=\left(\sum_{n=1}^{N} \eta_{j}^{\frac{1}{\chi}}\left(p_{n, i, t}^{J} m_{n, i, t}^{J}\right)^{\frac{\chi-1}{\chi}}\right)^{\frac{\chi}{\chi-1}}
$$

where now $V_{i, t}^{M}$ is a combination of $N$ distinct products, with weights $\eta_{j}$ and elasticity $\chi$.

Product-level heterogeneity in the production impact of the shock combined with imperfect coordination among input suppliers implies that the aggregate (measured) import bundle for a particular firm may turn out to be suboptimal. In this case, we are measuring $\widehat{V}_{i, t}^{M}=\sum_{n=1}^{N}\left(p_{n, t}^{m} m_{n, t}\right) \geq V_{i, t}^{M}$. And the lower the elasticity of substitution among products, the more severe the disconnect between the measured imports and the "effective" imports - that which is actually useful in downstream production.

A suboptimal product mix indicates that measured imports $\left(\widehat{V}^{M}{ }_{i, t}\right)$ are greater than the effective imports $\left(V_{i, t}^{M}\right)$. As a result the measured output response to the import shock will be larger than otherwise, resulting in a downward "bias" in the elasticity estimates from section 2.2 .3 and $3{ }^{48}$ Such an effect is decreasing in the product-level elasticity parameter $\chi$ itself, as complementarity

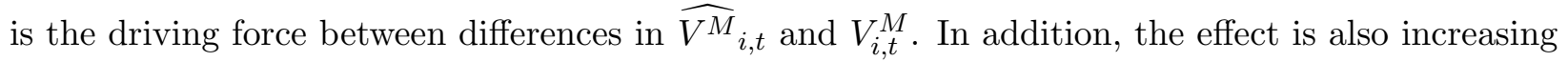
in the distance from the optimal product mix.

Does this exert a quantitatively large effect on our point estimates? Given the emphasis on low

\footnotetext{
${ }^{47}$ At first glance, the average monthly supply of these output inventories looks surprisingly low. On the other hand, it is probably the case that inventories are held jointly by the manufacturer and wholesale/retail establishments Thus, considering the inventories of manufacturers alone could potentially under-represent the "true" level of output inventories available for smoothing out production disturbances.

${ }^{48}$ Because the source of this downward pressure on the estimate for $\psi$ (or $\omega$ ) is itself a very low product-level elasticity, it is unclear whether this should be considered a bias in the traditional sense.
} 
inventories and lean production processes in downstream operations, one might expect that acrossproduct adjustment would take place before sending the inputs abroad. To analyze this empirically, we analyze whether there are significant deviations in the product composition of Japanese imports during the months following the Tōhoku event. To do this, we construct a measure of the distance of a firm's import bundle from a benchmark, which we will interpret to be the optimal bundle. Let $t=s^{*}$ be such a benchmark. Then, using the product-level information in the LFTTD data we construct for each firm $i$, the share of total imports from Japan for a given product code $n$. Defining this share to be $s_{n, i, t}$, we then construct the average product-level distance from optimum $D O_{i, t}$ as:

$$
D O_{i, t}=\frac{1}{N^{i}} \sum_{n=1}^{N^{i}}\left(\left|s_{n, i, t}-s_{i=n, i, s^{*}}\right|\right)
$$

where $N^{i}$ is the total number of products imported by firm $i$. We define the period $s^{*}$ to be the months of April-June of 2010, and then evaluate $D O_{i}$ at a monthly frequency, with particular interest in the months following the Tōhoku event. While there may be natural movements in the bundle of products imported from Japan, evidence for substantial coordination failure in product composition or heterogeneity in product-level shocks would come from any abnormal jumps in this index in the months of the disruption. One can calculate this at various levels of product aggregation (i.e. HS4, HS6, HS8, HS10), though we report results using the HS6 level 49

The results of this exercise are shown in Figure 9. We plot the average $D O_{i}$ across Japanese firms for each month (the figure shows a 3-month moving average) during the period 2009-2011. Mechanically, this measure should be relatively close to zero in the months consisting of the benchmark (April-June 2010). While there is a secular rise in this measure on either side of this benchmark period, there do not appear to be any large jumps in the months directly following the Tōhoku event. More interesting, perhaps, are the considerably larger values for this measure during early 2009, which might reflect the effects of the trade collapse associated with the Great Recession. We interpret Figure 9 as evidence that the potential for suboptimal mix across products from Japan does not pose a serious problem to our measurement in previous sections.

\footnotetext{
${ }^{49}$ The level of aggregation we use attempts to balance concerns along two dimensions. With less product aggregation (i.e. HS10 level), one might be concerned with the inherent lumpiness of product-level firm imports. More product aggregation, on the other hand, could mask important product differences within a particular product grouping.
} 


\subsubsection{Other Considerations}

Strategic Behavior: Another possibility that could affect the interpretation of the results from Figure 7 might be strategic behavior, particularly on the part of the competitors of Japanese firms in the United States. These firms could raise production or prices following the negative supply shock affecting their competitors, which would serve to bias downward the $\beta_{p}$ coefficients from the equation with $X_{i, t}^{N A}$ as the dependent variable 50 To evaluate this possibility, we turn once again to the automotive data. Here, we can look directly at the production of non-Japanese automakers in the months directly following the Tōhoku event. Appendix Figure A1 plots the relative production of these firms, using time-series variation only. There appears to be no quantitatively meaningful responses in the months following March 2011. This should not come as a surprise given capacity constraints and utilization adjustment costs, particularly given the short time horizon. We provide evidence on the role of prices next.

Prices: Traditionally, estimating the elasticity of substitution is accomplished via price and quantity data for products over extended periods of time. For the short horizon we consider in this paper, there are several reasons why prices may not have the scope to adjust. Many supplier relationships negotiate prices for longer periods of time than one or two months. Second, and perhaps more importantly, Tables 2 and 4 make clear that the large majority of imported intermediate inputs are intra-firm. The observed prices of these transactions are transfer-prices (within firm) and not likely to change reflecting any short-term disturbance. However, because the LFTTD contains both quantity and price information, we can confirm whether or not prices remained relatively stable during this period. The results in Appendix Table A4 confirm that there are few significant price movements on import or export transactions for either Japanese or non-Japanese multinationals surrounding the Tōhoku event 51

Domestic Inputs: It is also possible to evaluate the response of domestic inputs directly, using the limited information we have on quarterly firm-level employment and payroll information, taken from the Census Bureau's Business Register (BR) 52 We consider the evidence in Appendix C.2

\footnotetext{
${ }^{50}$ Specifically, in equation $(3)$ the $\gamma_{p} s$ would be higher than would be expected without the shock, and hence the $\beta_{p} s$ artificially low.

${ }^{51}$ Further details on the construction of the data underlying the analysis of unit values is available in Appendix C.3.

${ }^{2}$ The BR itself receives quarterly payroll and employment information for business and organizational employers from the IRS: Form 941, the Employer's Quarterly Federal Tax Return. For more information on the BR (formerly the SSEL), see Walker (1997).
} 
and find no significant effects on either employment or payroll for Japanese firms in the quarter(s) following the shock (see Table A3). Of course, there are a number of reasons — principally labor adjustment costs - why one would expect little, if any, impacts on employment following this shortlived shock. Press releases dispatched by the Japanese automakers during this time indicated that no layoffs would occur. Rather, the firms indicated that they would use the production stoppages for employee skill and safety training.

\subsection{External Validity}

Finally, we discuss the external validity of this result. The exogenous variation we use to identify this elasticity is tied to a particular event in time, making generalization subject to some caveats. On the other hand, there are few, if any, estimates of this parameter in the existing literature. The critical question is whether the mechanisms underlying the elasticity estimates are operative beyond the circumstances surrounding this event study.

When viewed in light of the substantial fraction of intra-firm imports comprising multinational affiliate trade, the low elasticity of substitution should not come as a surprise. One would not expect close substitutes for the sort of specialized products reflecting firm-specific knowledge that likely comprises this trade. Moreover, such a low estimate for an elasticity of this nature is not without precedent. Using different methodologies, recent work by Atalay (2014) highlights strong complementarities between intermediate inputs, using industry-level data for the United States 53

The pattern of strong intermediate input linkages with the source country is not restricted to Japanese affiliates only. As shown in Flaaen (2013b), over 45 percent of the imports for all foreign multinational affiliates are sourced from the country of the parent firm. The cost share of imported intermediates from the source country is 0.12 for all foreign affiliates, which is lower than the 0.22 for Japanese affiliates but still much larger than the representative importing firm in the United States.

Any elasticity estimate is tied to the time-horizon to which it corresponds. Work by Ruhl (2004) emphasizes the difference between elasticities implied by responses to temporary vs permanent shocks. Larger values are calculated for an elasticity following a permanent shock, owing in part to firm responses along the extensive margin. In our context, we estimate the elasticity

\footnotetext{
${ }^{53}$ The point estimate for the elasticity of substitution among intermediate inputs from Atalay (2014) is 0.03 .
} 
subject to a short-lived shock where the supply chain is plausibly fixed and extensive margin movements of supplier relationships would not apply. For this reason the elasticity parameters $(\omega, \zeta)$ should likely generalize to other contexts of this horizon and for shocks of this general duration. Even for a long-lived shock, the estimated elasticities would remain relevant while the firm makes changes to its network of suppliers. Evaluating whether there is evidence for long-term supply-chain reorganization following the Tōhoku event is an area of ongoing work.

\section{Conclusions}

Using a novel firm-level dataset to analyze firm behavior surrounding a large exogenous shock, this paper reveals the mechanisms underlying cross-country spillovers. We find strong rigidities in the international production networks of Japanese affiliates, such that the U.S. output of these firms declined dramatically following the Tōhoku earthquake, roughly in line with an equally large decline in imported inputs. The elasticity of substitution between imported and domestic inputs that would best match this behavior is very low - nearly that implied by a Leontief production function. The reliance on intra-firm imports by multinational affiliates from their source country is the most plausible explanation for such strong complementarities in production. Structural estimates of disaggregated elasticities are similarly low, and reveal evidence for spillovers to upstream and downstream firms in the U.S. and abroad (non-Japan). The large impacts to Japanese affiliates together with the propagation to other U.S. firms explains the large transmission of the shock to the U.S. economy in the aggregate.

These elasticities play a critical role in the way international trade impacts both source and destination economies. Such complementarities between domestic and foreign goods have been shown to improve the ability of leading theoretical models to fit key moments of the data. We emphasize here the distinction between substitutability between domestic and foreign final goods (a "consumption" elasticity of substitution, or the so-called Armington elasticity) and substitutability between domestic and foreign intermediate goods (a "production" elasticity of substitution). In a companion paper, we document the behavior of a model with such complementarities in imported intermediates, and discuss how these elasticity parameters interact. Calibrating this model to the share of multinational affiliate trade in intermediates yields an increase in value-added comovement of as much as 18 p.p., and reduces the gap between consumption and value-added comovement by 
a considerable margin.

Such rigid production networks will play a substantial role in aggregate volatility, productivity growth and dispersion, and the international ownership structure of production. The novel datasets described in this paper may help to shed light on these and other areas of research in the future. 


\section{References}

Ackerberg, Daniel A., Kevin Caves, and Garth Frazer. 2006. "Structural Identification of Production Functions." Working paper, University of Michigan.

Alviarez, Vanessa. 2014. "Multinational Production and Comparative Advantage." Working paper, University of Michigan.

Atalay, Enghin. 2014. "How Important Are Sectoral Shocks?" Working Paper.

Backus, David K., Patrick J. Kehoe, and Finn E. Kydland. 1994. "Dynamics of the Trade Balance and the Terms of Trade: The J-Curve?" American Economic Review 84 (1):84103.

. 1995. "International Business Cycles: Theory and Evidence." In Frontiers of Business Cycle Research, edited by Thomas F. Cooley. Princeton: Princeton University Press.

Bernard, Andrew, J. Bradford Jensen, Stephen J. Redding, and Peter K. Schott. 2007. "Firms in International Trade." Journal of Economic Perspectives 21 (3):105-130.

Bernard, Andrew, J. Bradford Jensen, and Peter K. Schott. 2006. "Transfer Pricing by U.S.-Based Multinational Firms." Working paper, Yale School of Management.

Blasnik, Michael. 2010. "RECLINK: A Stata Module to Probabilistically Match Records." Working paper.

Boehm, Christoph, Aaron Flaaen, and Nitya Pandalai Nayar. 2014. "The Role of Multinational Firms in Business Cycle Comovement." Working paper, University of Michigan.

Burstein, Ariel, Christopher Kurz, and Linda Tesar. 2008. "International Trade, Production Sharing and the Transmission of Business Cycles." Journal of Monetary Economics 44 (4):775-795.

Busso, Matias, John DiNardo, and Justin McCrary. 2014. "New Evidence on the Finite Sample Properties of Propensity Score Matching and Reweighting Estimators." Review of Economics and Statistics forthcoming.

Carvalho, Vasco M., Makoto Nirei, and Yukiko U. Sato. 2014. "Supply Chain Disruptions: Evidence from the Great East Japan Earthquake." Working paper.

Caselli, Francesco, Míklos Koren, Milan Lisicky, and Silvana Tenreyro. 2014. "Diversification through Trade." Working paper.

Cravino, Javier and Andrei Levchenko. 2014. "Multinational Firms and International Business Cycle Transmission." Working paper, University of Michigan.

di Giovanni, Julian and Andrei Levchenko. 2012. "Country Size, International Trade, and Aggregate Fluctuations in Granular Economies." Journal of Political Economy 120 (6):10831132. 
di Giovanni, Julian, Andrei Levchenko, and Isabelle Méjean. 2014. "Firms, Destinations, and Aggregate Fluctuations." Econometrica 82 (4):1303-1340.

Feenstra, Robert C., Philip A. Luck, Maurice Obstfeld, and Katheryn N. Russ. 2014. "In Search of the Armington Elasticity." Working paper.

Flaaen, Aaron. 2013a. "Constructing a Bridge Between the LexisNexis Directory of Corporate Affiliations and the U.S. Business Register." Working paper, University of Michigan.

—. 2013b. "Multinational Firms in Context." Working paper, University of Michigan.

Frankel, Jeffrey A. and Andrew K. Rose. 1998. "The Endogeneity of the Optimum Currency Area Criteria." Economic Journal 108 (449):1009-1025.

Gabaix, Xavier. 2011. "The Granular Origins of Aggregate Fluctuations." Econometrica 79:733-772.

Goldberg, Penelope, Amit Kumar Khandelwal, Nina Pavcnik, and Petia Topalova. 2010. "Imported Intermediate Inputs and Domestic Product Growth: Evidence from India." Quarterly Journal of Economics 125 (4):1727-1767.

Halpern, László, Miklós Koren, and Adam Szeidl. 2011. "Imported Inputs and Productivity." Working Paper.

Heathcote, Jonathan and Fabrizio Perri. 2002. "Financial Autarky and International Business Cycles." Journal of Monetary Economics 49:601-627.

Hirschmann, A.O. 1958. "Interdependence and Industrialization." In The Strategy of Economic Development. New Haven: Yale University Press.

Imbs, Jean. 2004. "Trade, Finance, Specialization, and Synchronization." Review of Economics and Statistics 86 (3):723-734.

Imbs, Jean and Isabelle Méjean. 2011. "Elasticity Optimism." Working Paper 7177, CEPR Discussion Paper.

Jarmin, Ron and Javier Miranda. 2002. "The Longitudinal Business Database." Mimeo, available at http://www.vrdc.cornell.edu/info7470/2007/Readings/jarmin-miranda2002.pdf.

Johnson, Robert C. 2014. "Trade in Intermediate Inputs and Business Cycle Comovement." American Economic Journal: Macroeconomics forthcoming.

Johnson, Robert C. and Guillermo Noguera. 2012. "Accounting for Intermediates: Production Sharing and Trade in Value Added." Journal of International Economics 86 (2):224236.

Jones, Charles I. 2011. "Intermediate Goods and Weak Links in the Theory of Economic Development." American Economic Journal: Macroeconomics 3 (2):1-28. 
Keller, Wolfgang and Stephen Yeaple. 2013. "The Gravity of Knowledge." American Economic Review 103 (4):1414-1444.

Kleinert, Jörn, Julien Martin, and Farid Toubal. 2012. "The Few Leading the Many: Foreign Affiliates and Business Cycle Comovement." Working Paper DP 9129, Center for Economic Performance.

Koren, Miklós and Silvana Tenreyro. 2013. "Technological Diversification." American Economic Review 103 (1):378-414.

Kremer, Michael. 1993. "The O-Ring Theory of Economic Development." Quarterly Journal of Economics 108 (3):551-575.

Kurz, Christopher Johann and Mine Zeynep Senses. 2013. "Importing, Exporting and FirmLevel Employment Volatility." Working Paper 2013-44, Board of Governors of the Federal Reserve System.

Leontief, Wassily. 1936. "Quantitative Input and Output Relations in the Economic Systems of the United States." The Review of Economics and Statistics 18 (3):105-125.

Peek, Joe and Eric S. Rosengren. 1997. "The International Transmission of Financial Shocks: The Case of Japan." American Economic Review 87 (4):495-505.

_. 2000. "Collateral Damage: Effects of the Japanese Bank Crisis on Real Activity in the United States." American Economic Review 90 (1):30-45.

Pierce, Justin and Peter Schott. 2012. "A Concordance Between U.S. Harmonized System Codes and SIC/NAICS Product Classes and Industries." Journal of Economic and Social Measurement 37 (1-2):61-96.

Ramey, Valerie A. 1989. "Inventories as Factors of Production and Economic Fluctuations." American Economic Review 79 (3):338-354.

Ramondo, Natalia, Veronica Rappoport, and Kim J. Ruhl. 2007. "Horizontal vs Vertical FDI: Revisiting Evidence from U.S. Multinationals." Working paper, Columbia Business School.

Ruhl, Kim J. 2004. "The International Elasticity Puzzle." Working paper, NYU Stern School of Business.

Schnell, Molly and David E. Weinstein. 2012. "Evaluating the Economic Response to Japan's Earthquake." Working Paper 12-P-003, RIETI.

Stern, Robert, Jonathan Francis, and Bruce Schumacher. 1976. "Price Elasticities in International Trade." In The Strategy of Economic Development. London: Macmillan.

Wald, Davis J, Bruce C. Worden, Vincent Quitoriano, and Kris L. Pankow. 2006. "ShakeMap Manual: Technical Manual, User's Guide and Software Guide." Tech. rep., U.S. Geological Survey. URL http://pubs.usgs.gov/tm/2005/12A01/. 
Walker, E. 1997. "The Census Bureau Business Register: Basic Features and Quality Issues." Paper presented at the Joint Statistical Meetings, Anaheim, CA.

Wasi, Nada and Aaron Flaaen. 2014. "Record Linkage Using Stata: Pre-Processing, Linking and Reviewing Utilities." Working paper, University of Michigan. 


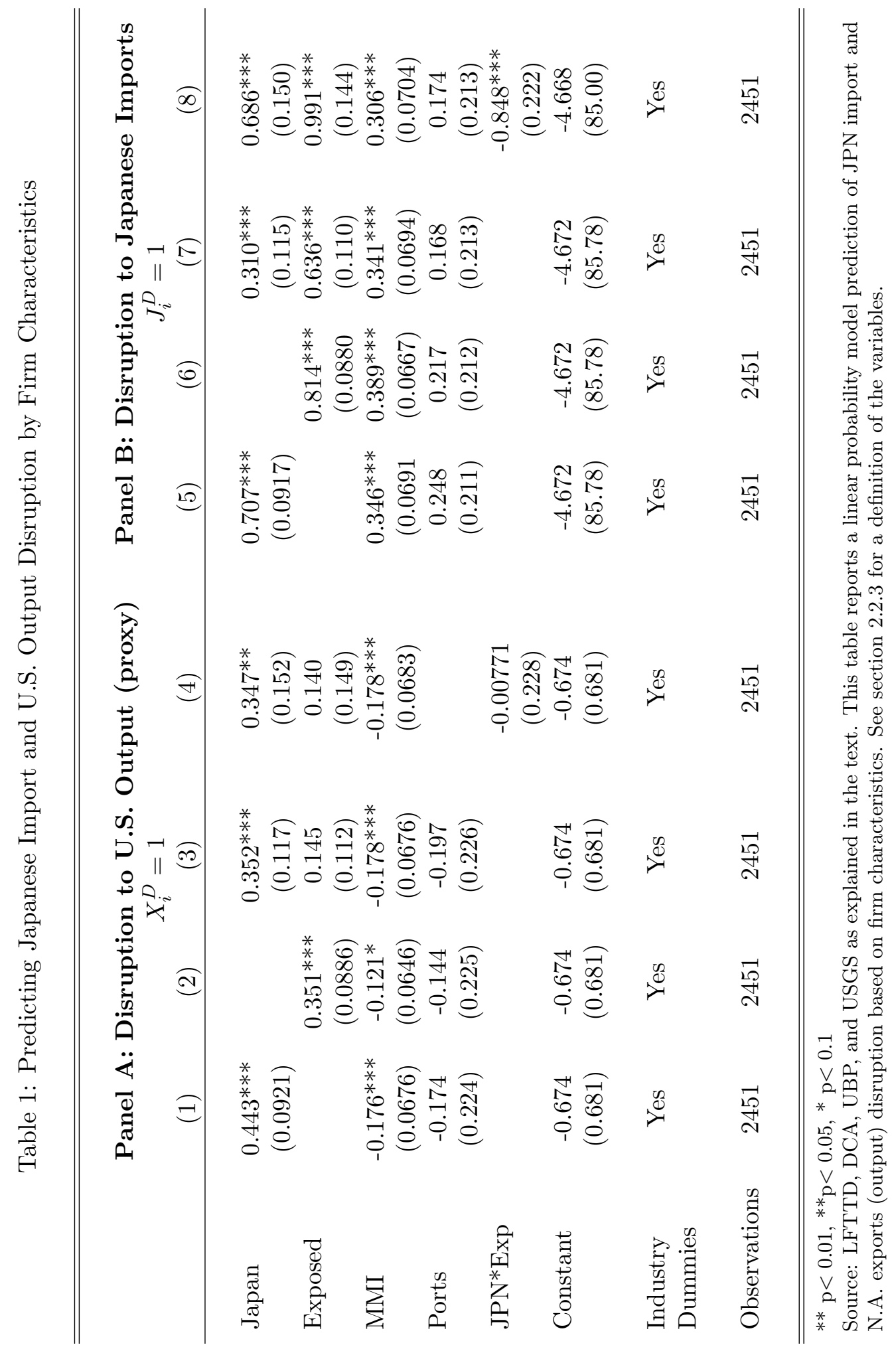


Table 2: Composition of Japanese Imports by Japanese Multinationals

\begin{tabular}{c}
\hline \hline Japanese \\
Multinationals \\
\hline
\end{tabular}

Share Intermediate

Share Related-Party

53.8

in intermediate imports $\quad 85.7$

in final imports $\quad 97.1$

Source: CM, LFTTD, DCA, and UBP as explained in the text. The data are for year 2007. This table reports the composition of Japanese imports from Japanese multinationals.

Table 3: Summary Statistics: Imported Inputs and Inventories by Firm Type

\begin{tabular}{lcc}
\hline \hline & $\begin{array}{c}\text { Japanese } \\
\text { Multinationals }\end{array}$ & $\begin{array}{c}\text { Non } \\
\text { Multinationals }\end{array}$ \\
\hline \multicolumn{3}{l}{ Panel A: Avg. Monthly Supply of Inventories } \\
Inputs & 0.83 & \\
Output & 0.31 & 1.08 \\
& & 0.45 \\
Panel B: Cost Share Of Imported Inputs & \\
from Japan & 21.8 & 1.0 \\
from all countries & 35.0 & 17.5 \\
& & \\
\hline \hline
\end{tabular}

Source: CM, LFTTD, DCA, and UBP as explained in the text. The data are for year 2007. This table reports the average monthly supply of inventories [(usage/12)/beginning period inventory stock] for materials and output, as well as the cost share of imported products. 
Table 4: Baseline Sample: Summary Statistics

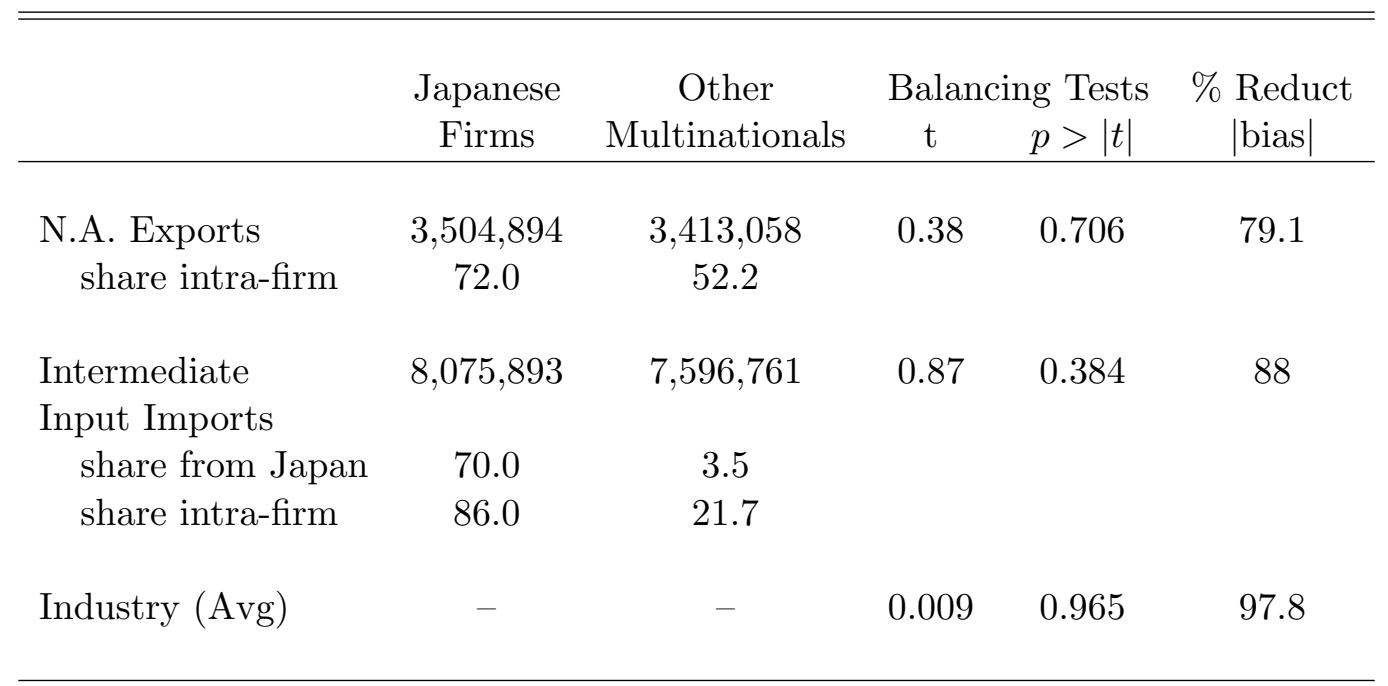

Source: LFTTD, DCA, and UBP as explained in the text.

This table reports the baseline average values of N.A. exports and intermediate input imports, as well as the characteristics of that trade, for the two groups of firms: Japanese affiliates and other multinational firms. The statistics are calculated in the three months prior to the Tōhoku earthquake: Dec. 2010, Jan. 2011, and Feb 2011. The control group of other multinational firms has been re-weighted using the normalized propensity score, from a specification including the level of N.A. exports, int imports, and industry dummies. The final three columns report balancing tests of the equality of the means between the treated and control group. 
Table 5: Firm-Level Estimation: Summary Statistics and Results

\begin{tabular}{|c|c|c|}
\hline \multicolumn{3}{|c|}{ Panel A: Calibration } \\
\hline Parameter & Value & Source/Justification \\
\hline $\begin{array}{l}\varepsilon \\
R_{t} \\
\alpha\end{array}$ & $\begin{array}{c}8 \\
0.07 \\
1 / 3\end{array}$ & various \\
\hline \multicolumn{3}{|c|}{ Panel B: Estimation Results } \\
\hline & $\begin{array}{c}\text { Japanese } \\
\text { Multinationals }\end{array}$ & $\begin{array}{l}\text { Non-Japanese } \\
\text { Multinationals }\end{array}$ \\
\hline$\omega$ & $\begin{array}{c}0.201 \\
(0.133)\end{array}$ & $\begin{array}{c}0.624 \\
(0.164)\end{array}$ \\
\hline$\zeta$ & $\begin{array}{c}0.032 \\
(0.279)\end{array}$ & $\begin{array}{c}0.038 \\
(0.142)\end{array}$ \\
\hline & \multicolumn{2}{|c|}{ Sample Details } \\
\hline $\begin{array}{l}\text { Weight on } \mathrm{K} / \mathrm{L} \\
\text { Aggregate }(\bar{\mu})\end{array}$ & 0.223 & 0.514 \\
\hline $\begin{array}{l}\text { Weight on JPN } \\
\text { Materials }(1-\bar{\nu})\end{array}$ & 0.173 & 0.044 \\
\hline $\begin{array}{l}\text { Number of Firms } \\
\text { Share of Total Trade }\end{array}$ & 105 & 304 \\
\hline JPN int imports & 0.60 & 0.23 \\
\hline Non-JPN int imports & 0.02 & 0.66 \\
\hline N.A. exports & 0.08 & 0.47 \\
\hline
\end{tabular}

Source: CM, LFTTD, DCA, and UBP as explained in the text.

This table reports the results from the firm-level estimation detailed in section 3 Panel A outlines the parameters that are calibrated prior to estimation. The top two rows of Panel B reports the point estimates of the elasticities, and the corresponding bootstrapped standard errors. Rows 3 and 4 report other estimates related to the calculated production functions. The final rows of Panel B describe features of the two estimation samples. 
Figure 1: Index of Japanese Industrial Production: Manufacturing Jan.2010 - Jan-2012

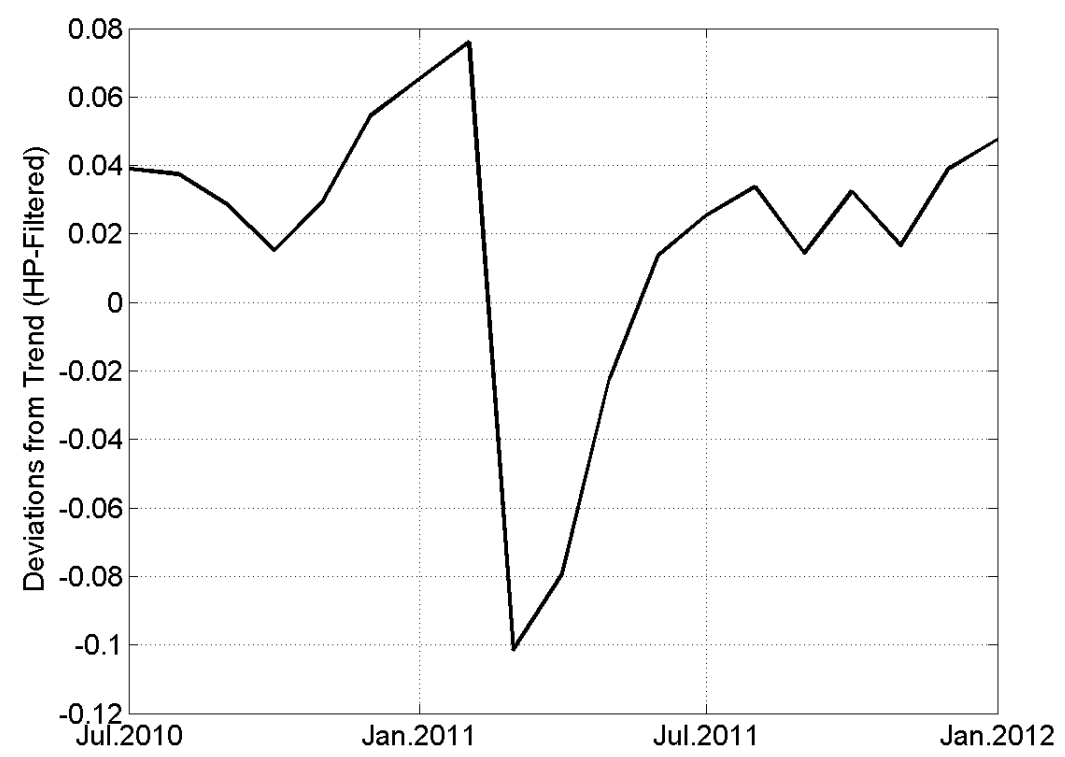

Source: Japanese Ministry of Economy, Trade, and Industry (METI). The series are logged, HP-Filtered, after seasonally adjusting.

Figure 2: U.S. Imports from Japan and Rest of World, Jan.2010 - Jan-2012

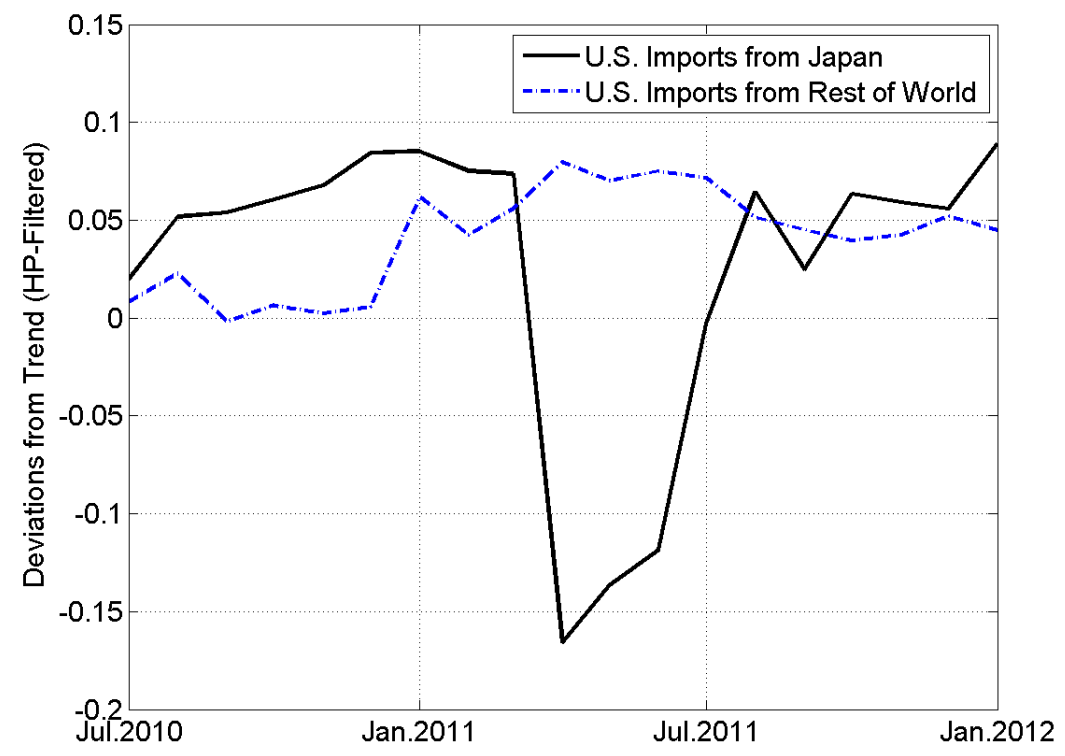

Source: U.S. Census Bureau, based on Published Totals. The series are logged, HP-Filtered, after seasonally adjusting. 
Figure 3: U.S. Industrial Production: Manufacturing and Durable Goods

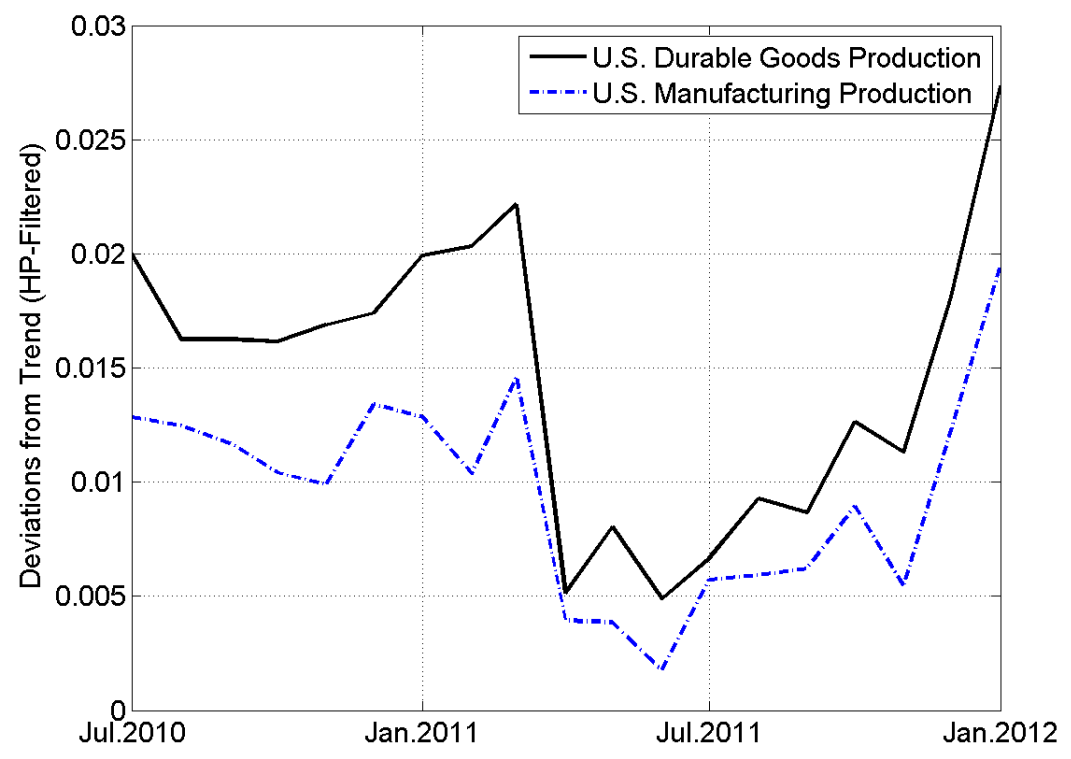

Source: Federal Reserve Board. Series is Seasonally Adjusted. 
Figure 4: Geographic Distribution of Earthquake Intensity and Affiliate Locations

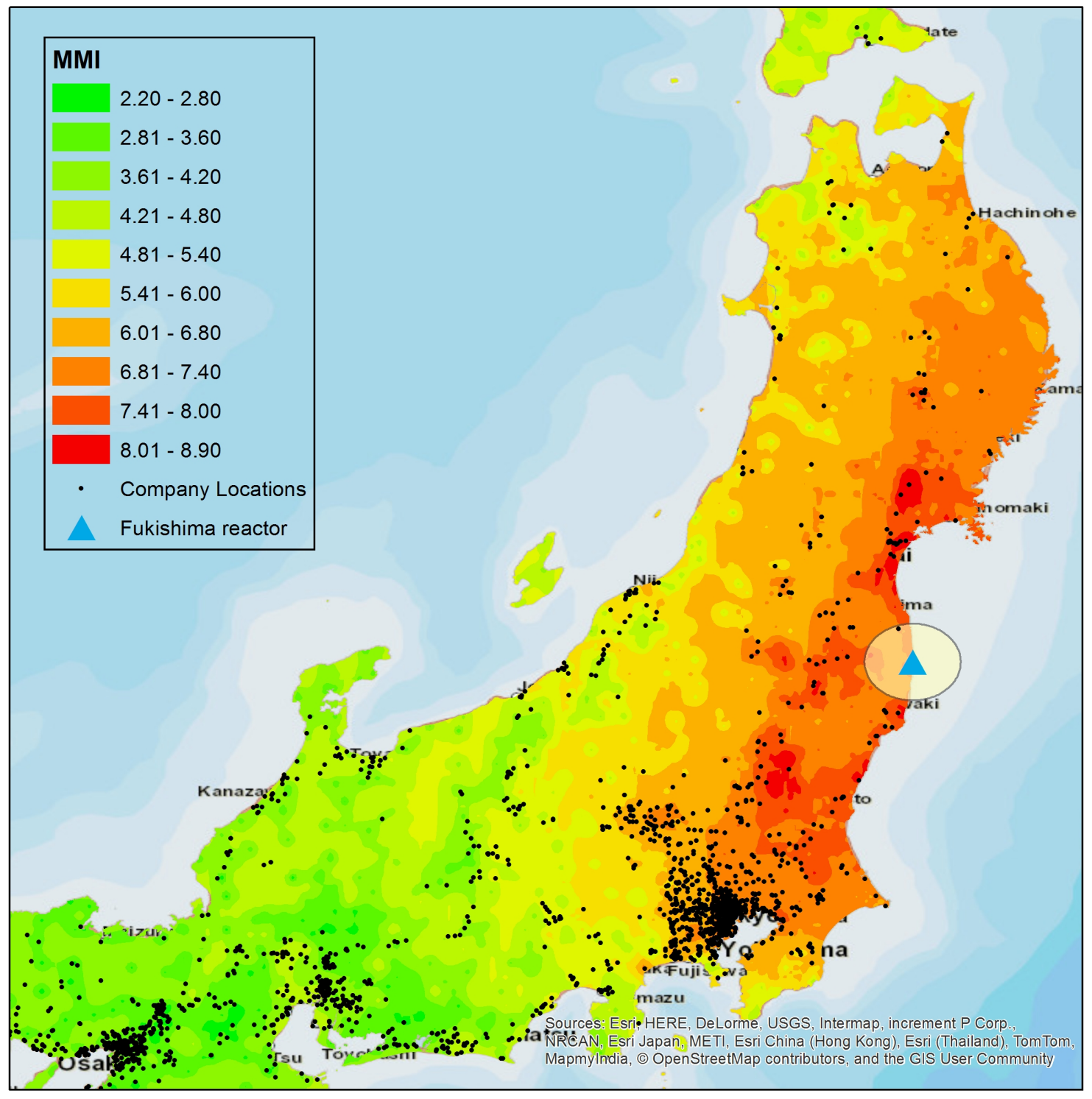

Source: USGS and DCA/Uniworld Directories

This figure plots the geographic distribution of the Tōhoku earthquake, based on recorded measurements taken directly after the event. The "Modified Mercalli Intensity" (MMI) scale is constructed based on a relation of survey response and measured peak acceleration and velocity amplitudes from prior major seismic events. Each dot corresponds to a geocoded Japanese affiliate location corresponding to a firm with U.S. operations. For more details, see Appendix B.3.2 
Figure 5: Density of Firm-Level Exposure to Japanese Imported Inputs: By Firm Type

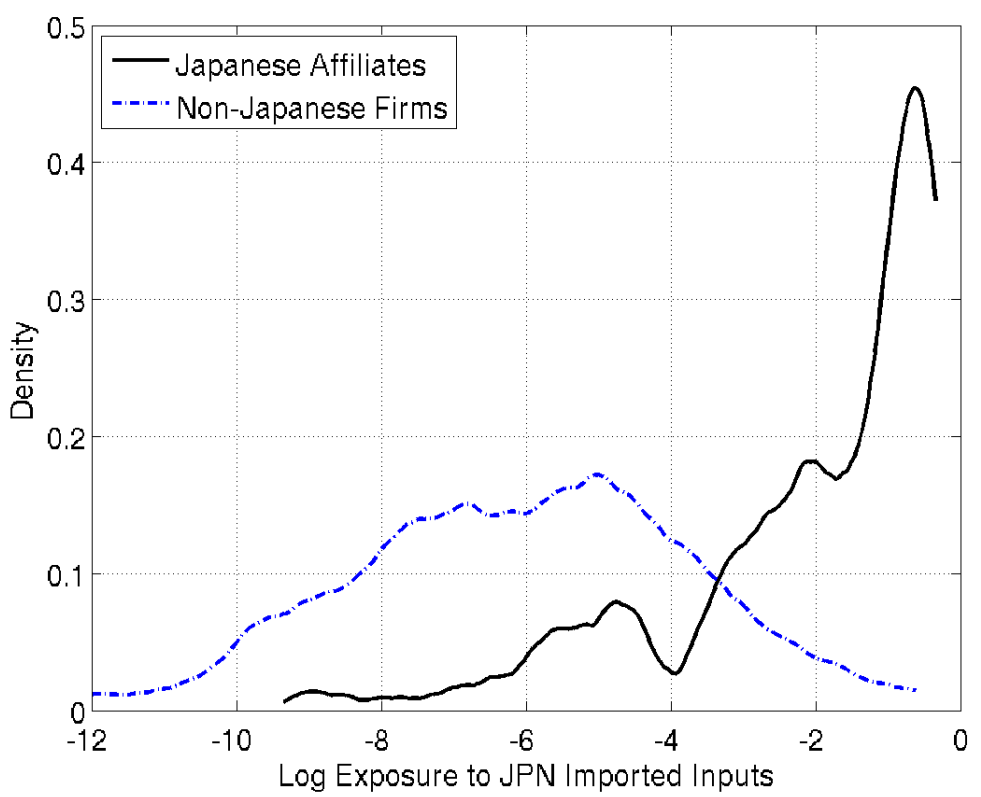

Source: LFTTD-DCA-UBP as explained in text.

This figure displays density estimates of the (log) exposure measure to Japanese imported inputs, separately for Japanese affiliates and non-Japanese multinational firms. The estimates correspond to year 2010. The exposure measure is defined as the ratio of Japanese imported inputs to total imported inputs plus U.S. salaries and wages. It is equivalent to the cost share measure shown in table 3 with the omission of domestic material usage and investment expenditures. Density estimates at either tail are suppressed for purposes of confidentiality. 
Figure 6: Dynamic Treatment Effects: Japanese Firms

\section{A. Relative Intermediate Input Imports of Japanese Firms}

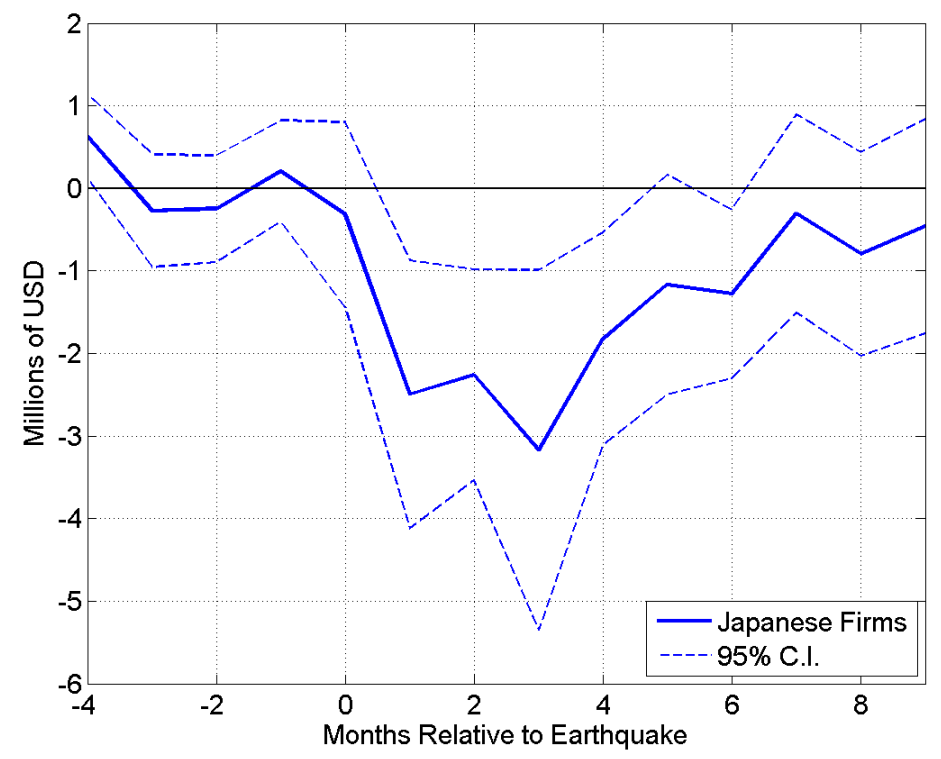

\section{B. Relative North American Exports of Japanese Firms}

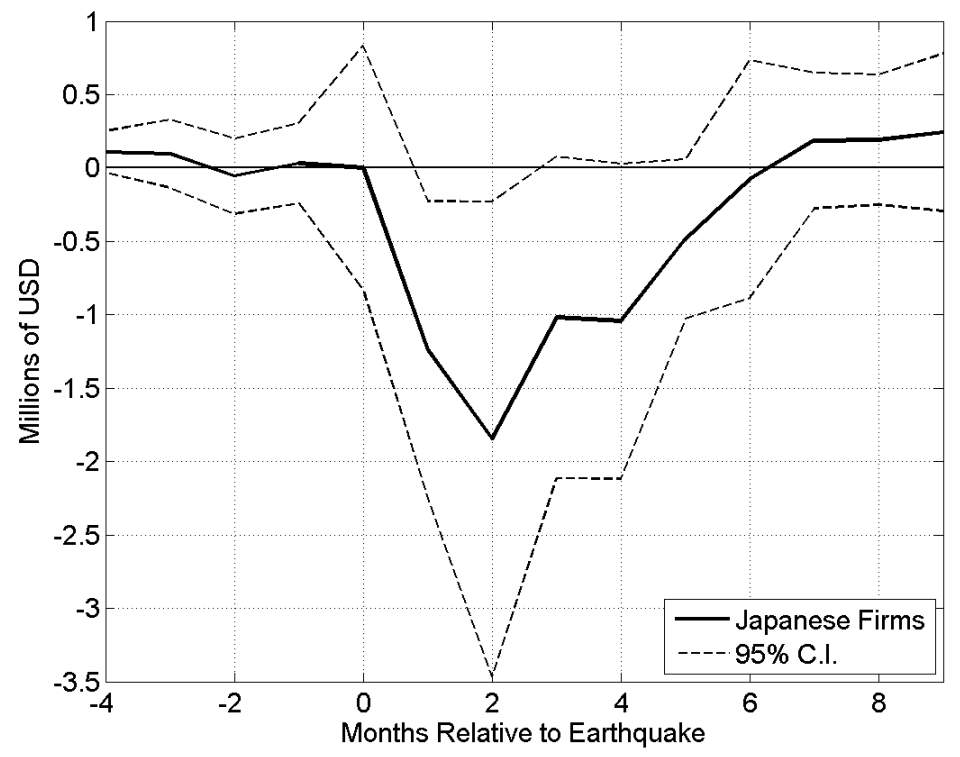

Source: LFTTD-DCA-UBP as explained in text.

These figures report the intermediate imports and North American exports of the U.S. affiliates of Japanese firms relative to a control group of other multinational firms. The values are coefficient estimates taken from an interaction of a Japanese-firm dummy with a monthly dummy - additional baseline monthly dummies remove seasonal effects. See equation 3 in the text. Standard errors are clustered at the firm level. 
Figure 7: Relative Imported Inputs and Output (Proxy) of Japanese Firms: Fraction of Pre-Shock Level

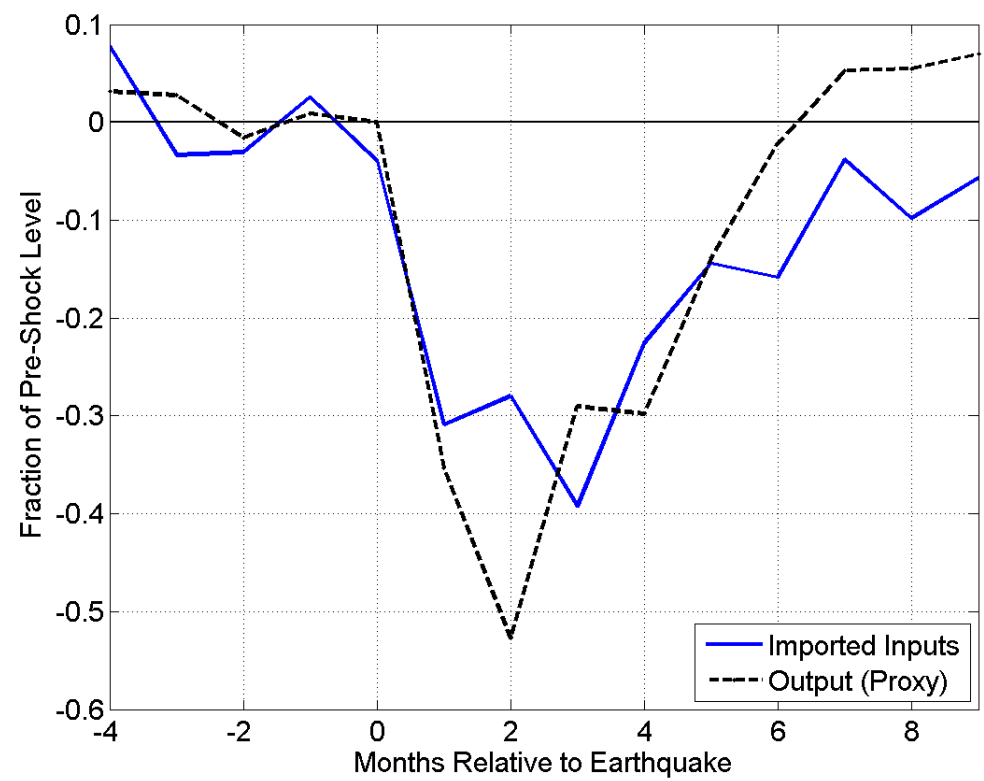

Source: LFTTD-DCA-UBP as explained in text.

This figure reports the intermediate imports and output proxy (North American exports) of the U.S. affiliates of Japanese firms relative to a control group of other multinational firms. The values are percent changes from the pre-shock level of each series, defined as the average of the months December 2010, January 2011, and February 2011. 
Figure 8: North America: Relative Production of Japanese Automotive Plants

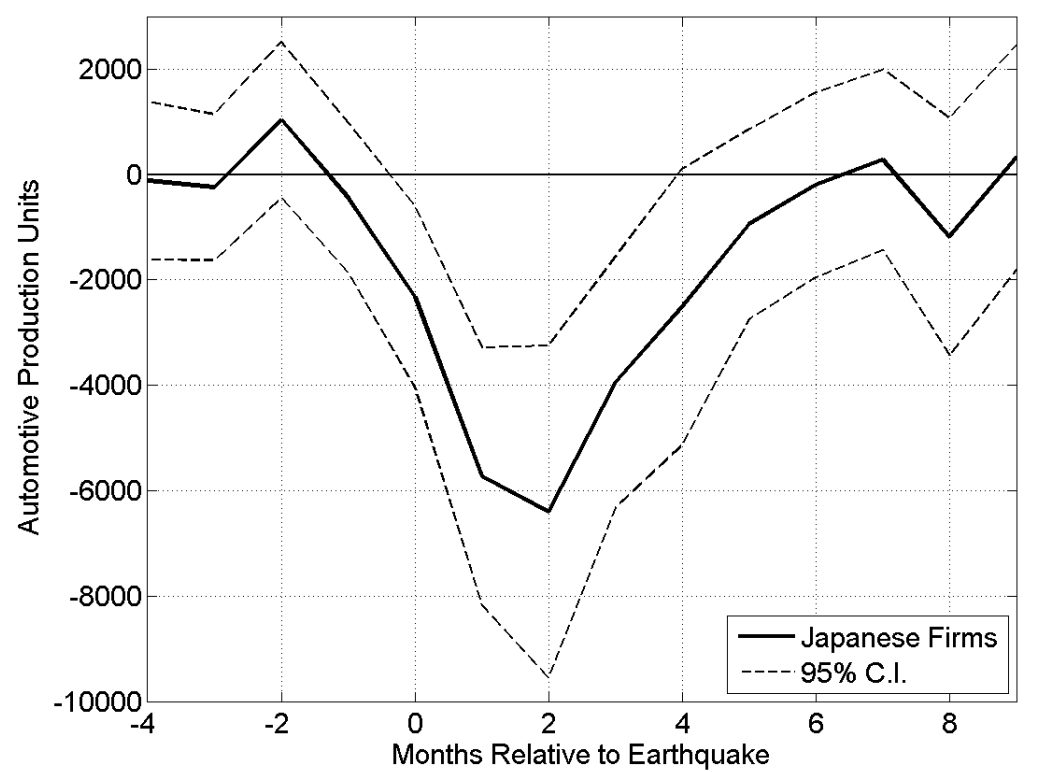

Source: Ward's Automotive Database

This figure reports the production levels of Japanese auto plants relative to a control group of non-Japanese auto plants. The values are coefficient estimates taken from an interaction of a Japanese-firm dummy with a monthly dummy - additional baseline monthly dummies remove any seasonal effects. See equation A8 in the text. Standard errors are clustered at the plant level. The Japanese automakers are Honda, Mazda, Mitsubishi, Nissan, Toyota, and Subaru. See section C.4 for more details. 
Figure 9: Japanese Products: Average Distance from Benchmark Cost Shares: JPN Multinationals

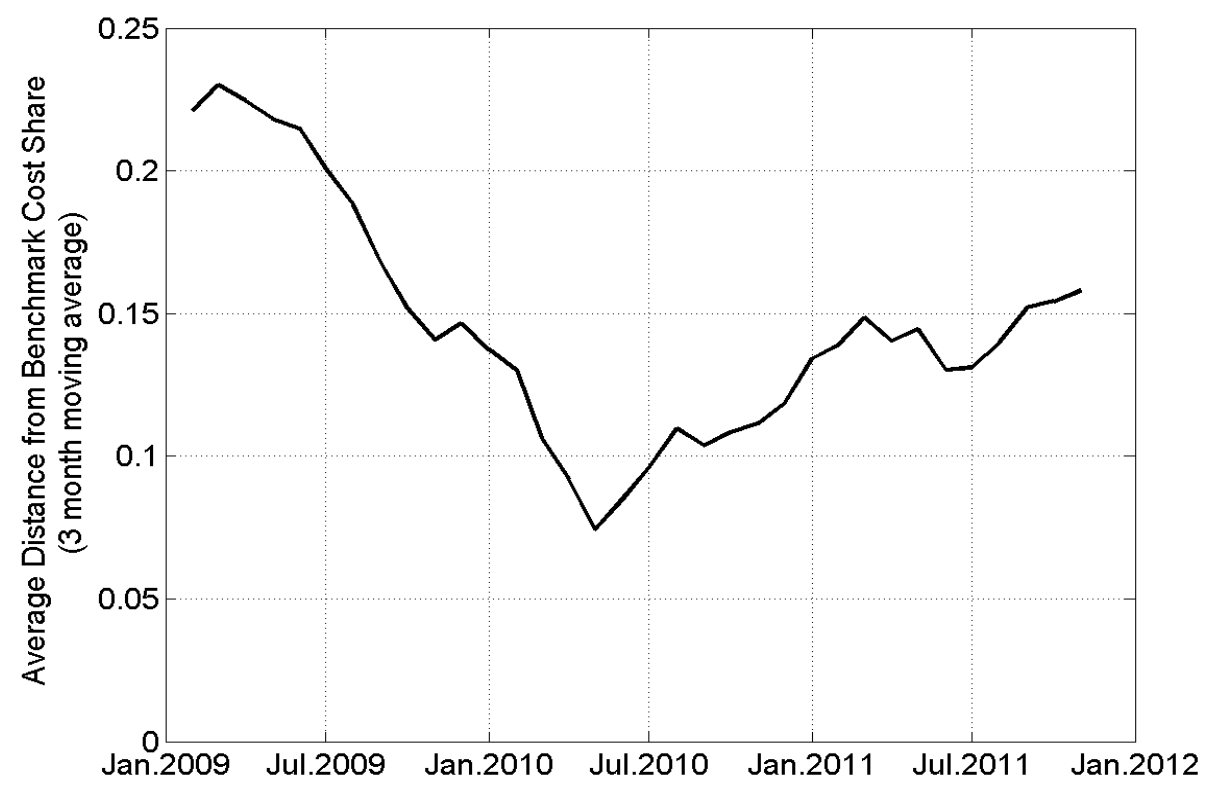

Source: LFTTD-DCA-UBP as explain in the text

Underlying this figure is the calculation of the average total (absolute) deviations from a benchmark measure of a firm's cost shares across input products from Japan. See equation 15 in the text. The figure reports the mean across the Japanese multinationals used in the section 3 


\section{A Mapping the Output Elasticity into the Elasticity of Substitu- tion}

Proof of Result 1

The first assumption allows us to equate the movements in dollar values that we observe in the data with movements in quantities. The second assumption allows us to separate out the $\psi$ parameter from a product-level elasticity, the failure of which we evaluate in section 4.2.3. The final assumption implies that the firm receives less $M^{J}$ than it would optimally require. We will observe $\frac{d l n x}{d \ln M^{J}}$ in the data:

$$
\frac{d \ln x}{d \ln M^{J}}=\frac{d \ln x}{d M^{J}} \frac{d M^{J}}{d \ln M^{J}}
$$

It is easy to show that $\frac{d M^{J}}{d \ln M^{J}}=M^{J}$, and so we are left with $\frac{d l n x}{d M^{J}}$

$$
\begin{aligned}
\ln x & =\frac{\psi}{\psi-1} \ln \left(\left[(1-\mu)^{\frac{1}{\psi}}\left[F_{D}(\cdot)\right]^{\frac{\psi-1}{\psi}}+\mu^{\frac{1}{\psi}}\left[M^{J}\right]^{\frac{\psi-1}{\psi}}\right]\right) \\
\frac{d l n x}{d M^{J}} & =\frac{\mu\left(M^{J}\right)^{\frac{\psi-1}{\psi}}-1}{(1-\mu)^{\frac{1}{\psi}}\left[F_{D}(\cdot)\right]^{\frac{\psi-1}{\psi}}+\mu^{\frac{1}{\psi}}\left[M^{J}\right]^{\frac{\psi-1}{\psi}}}
\end{aligned}
$$

Combining we have the following expression:

$$
\frac{d \ln x}{d \ln M^{J}}=\frac{\mu^{\frac{1}{\psi}}\left(M^{J}\right)^{\frac{\psi-1}{\psi}}}{(1-\mu)^{\frac{1}{\psi}}\left[F_{D}(\cdot)\right]^{\frac{\psi-1}{\psi}}+\mu^{\frac{1}{\psi}}\left[M_{t}^{J}\right]^{\frac{\psi-1}{\psi}}}
$$

To continue, we establish the sign of the derivative of equation (A4) with respect to $\psi$, and then check the bounds of the parameter space $(0, \infty)$ separately.

Output Elasticity for $\psi \in(0, \infty)$

We evaluate the following expression:

$$
\frac{\partial \frac{d \ln x}{d \ln M^{J}}}{\partial \psi}
$$

For ease of exposition let $\gamma \equiv \frac{M^{J}}{F_{D}(\cdot)}$. Then: 


$$
\begin{aligned}
& \frac{\partial \frac{d \ln x}{\operatorname{dn} M^{j}}}{\partial \psi}=\frac{\mu^{\frac{1}{\psi}} \gamma^{\frac{\psi-1}{\psi}} \frac{1}{\psi^{2}}(\ln \gamma-\ln \mu)\left((1-\mu)^{\frac{1}{\psi}}+\mu^{\frac{1}{\psi}} \gamma^{\frac{\psi-1}{\psi}}\right)-\left(-(1-\mu)^{\frac{1}{\psi}} \ln (1-\mu)+\mu^{\frac{1}{\psi}} \gamma^{\frac{\psi-1}{\psi}}(\ln \gamma-\ln \mu)\right) \mu^{\frac{1}{\psi}} \gamma^{\frac{\psi-1}{\psi}} \frac{1}{\psi^{2}}}{\left((1-\mu)^{\frac{1}{\psi}}+\mu^{\frac{1}{\psi}} \gamma^{\frac{\psi}{\psi}} \frac{1}{\psi}\right)^{2}} \\
& =\frac{\mu^{\frac{1}{\psi}} \gamma^{\frac{\psi-1}{\psi}}\left[(\ln \gamma-\ln \mu)\left((1-\mu)^{\frac{1}{\psi}}+\mu^{\frac{1}{\psi}} \gamma^{\frac{\psi \psi}{\psi}}\right)-\left(-(1-\mu)^{\frac{1}{\psi}} \ln (1-\mu)+\mu^{\frac{1}{\psi}} \gamma^{\frac{\psi-1}{\psi}}(\ln \gamma-\ln \mu)\right)\right]}{\psi^{2}\left((1-\mu)^{\frac{1}{\psi}}+\mu^{\frac{1}{\psi}} \gamma^{\frac{\psi-1}{\psi}}\right)^{2}} \\
& =\frac{\mu^{\frac{1}{\psi}} \gamma^{\frac{\psi \psi}{\psi}}\left[(1-\mu)^{\frac{1}{\psi}} \ln \gamma-(1-\mu)^{\frac{1}{\psi}} \ln \mu+\mu^{\frac{1}{\psi}} \gamma^{\frac{\psi-1}{\psi}} \ln \gamma-\mu^{\frac{1}{\psi}} \gamma^{\frac{\psi-1}{\psi}} \ln \mu+(1-\mu)^{\frac{1}{\psi}} \ln (1-\mu)-\mu^{\frac{1}{\psi}} \gamma^{\frac{\psi-1}{\psi}}(\ln \gamma-\ln \mu)\right]}{\psi^{2}\left((1-\mu)^{\frac{1}{\psi}}+\mu^{\frac{1}{\psi}} \gamma^{\frac{\psi-1}{\psi}}\right)^{2}} \\
& =\frac{\mu^{\frac{1}{\psi}} \gamma^{\frac{\psi-1}{\psi}}\left[(1-\mu)^{\frac{1}{\psi}} \ln \gamma-(1-\mu)^{\frac{1}{\psi}} \ln \mu+(1-\mu)^{\frac{1}{\psi}} \ln (1-\mu)\right]}{\psi^{2}\left((1-\mu)^{\frac{1}{\psi}}+\mu^{\frac{1}{\psi}} \gamma^{\frac{\psi-1}{\psi}}\right)^{2}} \\
& =\frac{\mu^{\frac{1}{\psi}}(1-\mu)^{\frac{1}{\psi}} \gamma^{\frac{\psi-1}{\psi}}[\ln \gamma-\ln \mu+\ln (1-\mu)]}{\psi^{2}\left((1-\mu)^{\frac{1}{\psi}}+\mu^{\frac{1}{\psi}} \gamma^{\frac{\psi-1}{\psi}}\right)^{2}}
\end{aligned}
$$

Since $\mu^{\frac{1}{\psi}}>0$ and $(1-\mu)^{\frac{1}{\psi}}>0 \forall \psi$, the sign of this expression is determined by the term in brackets within the numerator:

$$
\left(\ln \left(\frac{M^{J}}{F_{D}(\cdot)}\right)-\ln \mu+\ln (1-\mu)\right)
$$

According to assumption iii), we are in the case where $\frac{M^{J}}{F_{D}(\cdot)}<\frac{\mu}{1-\mu}$. For ease of exposition, we then re-write $\frac{M^{J}}{F_{D}(\cdot)}=x \frac{\mu}{1-\mu}$ where $x<1$. Then:

$$
\left(\ln \left(\frac{M^{J}}{F_{D}(\cdot)}\right)-\ln \mu+\ln (1-\mu)\right)=\ln (x)<0 \quad \text { since } \quad x<1
$$

Thus, the output elasticity is decreasing in $\psi$ provided that $\frac{M^{J}}{F_{D}(\cdot)}<\frac{\mu}{1-\mu}$. The magnitude of this correspondence depends on $\psi$ itself as well as the deviation from the optimal input mix. For completeness, we now show the behavior of $\frac{d \ln x}{d \ln M^{J}}$ as $\psi \rightarrow 0$ and as $\psi \rightarrow \infty$

Output Elasticity as $\psi \rightarrow 0$

Re-organizing and taking the limits of equation (A4) as $\psi \rightarrow 0$ :

$$
\lim _{\psi \rightarrow 0^{+}} \frac{d \ln x}{d \ln M^{J}}=\frac{\lim _{\psi \rightarrow 0^{+}} \mu^{\frac{1}{\psi}}\left(\frac{M^{J}}{F_{D}(\cdot)}\right)^{\frac{\psi-1}{\psi}}}{\lim _{\psi \rightarrow 0^{+}}(1-\mu)^{\frac{1}{\psi}}+\lim _{\psi \rightarrow 0^{+}} \mu^{\frac{1}{\psi}}\left[\frac{M^{J}}{F_{D}(\cdot)}\right]^{\frac{\psi-1}{\psi}}}
$$

Once again we rely on the assumption that $\frac{M^{J}}{F_{D}(\cdot)}<\frac{\mu}{1-\mu}$. Re-writing $\frac{M^{J}}{F_{D}(\cdot)}=x \frac{\mu}{1-\mu}$ where $x<1$ we have: 


$$
\lim _{\psi \rightarrow 0^{+}} \frac{d \ln x}{d \ln M^{J}}=\frac{\lim _{\psi \rightarrow 0^{+}} \mu x^{\frac{\psi-1}{\psi}}}{\lim _{\psi \rightarrow 0^{+}}(1-\mu)+\lim _{\psi \rightarrow 0^{+}} \mu x^{\frac{\psi-1}{\psi}}}=\frac{\infty}{(1-\mu)+\infty}=1
$$

Output Elasticity as $\psi \rightarrow \infty$

Intuitively we know that this approximates the relationship of perfect substitutes, and the two inputs can be used interchangeably.

$$
\lim _{\psi \rightarrow \infty} \frac{d \ln x}{d \ln M^{J}}=\frac{\lim _{\psi \rightarrow \infty} \mu^{\frac{1}{\psi}}\left(\frac{M^{J}}{F_{D}(\cdot)}\right)^{\frac{\psi-1}{\psi}}}{\lim _{\psi \rightarrow \infty}(1-\mu)^{\frac{1}{\psi}}+\lim _{\psi \rightarrow \infty} \mu^{\frac{1}{\psi}}\left[\frac{\left.M^{J} \cdot\right]^{\frac{\psi-1}{\psi}}}{F_{D}(\cdot)}\right.}
$$

Because $\mu<1$, then $\lim _{\psi \rightarrow \infty} \mu^{\frac{1}{\psi}}=1$ and $\lim _{\psi \rightarrow \infty}(1-\mu)^{\frac{1}{\psi}}=1$. And because $\lim _{\psi \rightarrow \infty} \frac{\psi-1}{\psi}=$ 1 we know $\lim _{\psi \rightarrow \infty}\left(\frac{M^{J}}{F_{D}(\cdot)}\right)^{\frac{\psi-1}{\psi}}=\frac{M^{J}}{F_{D}(\cdot)}$. So, putting this together we have:

$$
\lim _{\psi \rightarrow \infty} \frac{d \ln x}{d \ln M^{J}}=\frac{\frac{M^{J}}{F_{D}(\cdot)}}{1+\frac{M^{J}}{F_{D}(\cdot)}}=\frac{M^{J}}{F_{D}(\cdot)+M^{J}}
$$

This analysis makes sense. If there is a suboptimal mix of the two inputs under a (nearly) Leontief relationship (as $\psi \rightarrow 0$ ), the non-scarce input has essentially no impact on output. On the other hand, movements in the scarce input will transfer one for one to output. In addition, one can see that the effect is increasing in the distance from $\mu$, the optimal allocation between $F_{D}(\cdot)$ and $M^{J}$.

The case when $\psi \rightarrow \infty$ is similarly intuitive: Beginning from a steady state where there exists an optimal allocation between the two inputs, then the effect on output will simply be $\mu$, the share of the imported input. Here the effect will depend on the relative proportions between the two inputs, whereas on the other side of the parameter space of $\psi$, the effect depended simply on the relative scarcity. 


\section{B Data Appendix}

\section{B.1 Matching Corporate Directories to the Business Register}

The discussion below is an abbreviated form of the full technical note (see Flaaen (2013a)) documenting the bridge between the DCA and the Business Register.

\section{B.1.1 Directories of International Corporate Structure}

The LexisNexis Directory of Corporate Affiliations (DCA) is the primary source of information on the ownership and locations of U.S. and foreign affiliates. The DCA describes the organization and hierarchy of public and private firms, and consists of three separate databases: U.S. Public Companies, U.S. Private Companies, and International - those parent companies with headquarters located outside the United States. The U.S. Public database contains all firms traded on the major U.S. exchanges, as well as major firms traded on smaller U.S. exchanges. To be included in the U.S. Private database, a firm must demonstrate revenues in excess of $\$ 1$ million, 300 or more employees, or substantial assets. Those firms included in the International database, which include both public and private companies, generally have revenues greater than $\$ 10$ million. Each database contains information on all parent company subsidiaries, regardless of the location of the subsidiary in relation to the parent.

The second source used to identify multinational firms comes from Uniworld Business Publications (UBP). This company has produced periodic volumes documenting the locations and international scope of i) American firms operating in foreign countries; and ii) foreign firms with operations in the United States. Although only published biennially, these directories benefit from a focus on multinational firms, and from no sales threshold for inclusion.

Because there exist no common identifiers between these directories and Census Bureau data infrastructure, we rely on probabilistic name and address matching - so-called "fuzzy merging" - to link the directories to the Census data infrastructure.

\section{B.1.2 Background on Name and Address Matching}

Matching two data records based on name and address information is necessarily an imperfect exercise. Issues such as abbreviations, misspellings, alternate spellings, and alternate name conventions rule out an exact merging procedure, leaving the researcher with probabilistic string matching algorithms that evaluate the "closeness" of match - given by a score or rank - between the two character strings in question. Due to the large computing requirements of these algorithms, it is common to use so-called "blocker" variables to restrict the search samples within each dataset. A "blocker" variable must match exactly, and as a result this implies the need for a high degree of conformity between these variables in the two datasets. In the context of name and address matching, the most common "blocker" variables are the state and city of the establishment.

The matching procedure uses a set of record linking utilities described in Wasi and Flaaen (2014). This program uses a bigram string comparator algorithm on multiple variables with 
differing user-specified weights. ${ }^{54}$ This way the researcher can apply, for example, a larger weight on a near name match than on a perfect zip code match. Hence, the "match score" for this program can be interpreted as a weighted average of each variable's percentage of bigram character matches.

\section{B.1.3 The Unit of Matching}

The primary unit of observation in the DCA, UBP, and BR datasets is the business establishment. Hence, the primary unit of matching is the establishment, and not the firm. However, there are a number of important challenges with an establishment-to-establishment link. First, the DCA (UBP) and BR may occasionally have differing definitions of the establishment. One dataset may separate out several operating groups within the same firm address (i.e. JP Morgan - Derivatives, and JP Morgan - Emerging Markets), while another may group these activities together by their common address. Second, the name associated with a particular establishment can at times reflect the subsidiary name, location, or activity (i.e. Alabama plant, processing division, etc), and at times reflect the parent company name. Recognizing these challenges, the primary goal of the matching will be to assign each DCA (UBP) establishment to the most appropriate business location of the parent firm identified in the BR. As such, the primary matching variables will be the establishment name, along with geographic indicators of street, city, zip code, and state.

\section{B.1.4 The Matching Process: An Overview}

The danger associated with probabilistic name and address procedures is the potential for false-positive matches. Thus, there is an inherent tension for the researcher between a broad search criteria that seeks to maximize the number of true matches and a narrow and exacting criteria that eliminates false-positive matches. The matching approach used here is conservative in the sense that the methodology will favor criteria that limit the potential for false positives at the potential expense of slightly higher match rates. As such, the procedure generally requires a match score exceeding 95 percent, except in those cases where ancillary evidence provides increased confidence in the match 55

This matching proceeds in an iterative fashion, in which a series of matching procedures are applied with decreasingly restrictive sets of matching requirements. In other words, the initial matching attempt uses the most stringent standards possible, after which the non-matching records proceed to a further matching iteration, often with less stringent standards. In each iteration, the matching records are assigned a flag that indicates the standard associated with the match.

See Table A1 for a summary of the establishment-level match rate statistics by year and type of firm.

\footnotetext{
${ }^{54}$ The term bigram refers to two consecutive characters within a string (the word bigram contains 5 possible bigrams: "bi", "ig", "gr", "ra", and "am"). The program is a modified version of Blasnik (2010), and assigns a score for each variable between the two datasets based on the percentage of matching bigrams. See Flaaen (2013a) or Wasi and Flaaen (2014) for more information.

${ }^{\top}$ The primary sources of such ancillary evidence are clerical review of the matches, and additional parent identifier matching evidence.
} 


\section{B.1.5 Construction of Multinational Indicators}

The DCA data allows for the construction of variables indicating the multinational status of the U.S.-based establishment. If the parent firm contains addresses outside of the United States, but is headquartered within the U.S., we designate this establishment as part of a U.S. multinational firm. If the parent firm is headquartered outside of the United States, we designate this establishment as part of a Foreign multinational firm. We also retain the nationality of parent firm. 56

There can be a number of issues when translating the DCA-based indicators through the DCA-BR bridge for use within the Census Bureau data architecture. First, there may be disagreements between the DCA and Census on what constitutes a firm, such that an establishment matches may report differing multinational indicators for the same Censusidentified firm. Second, such an issue might also arise due to joint-ventures. Finally, incorrect matches may also affect the degree to which establishment matches agree when aggregated to a firm definition. To address these issues, we apply the following rules when using the DCA-based multinational indicators and aggregating to the (Census-based) firm level. There are three potential cases: 57

Potential 1: A Census-identified firm in which two or more establishments match to different foreign-country parent firms

1. Collapse the Census-identified firm employment based on the establishment-parent firm link by country of foreign ownership

2. Calculate the firm employment share of each establishment match

3. If one particular link of country of foreign ownership yields an employment share above 0.75, apply that link to all establishments within the firm.

4. If one particular link of country of foreign ownership yields an employment share above 0.5 and total firm employment is below 10,000, then apply that link to all establishments within the firm.

5. All other cases require manual review.

Potential 2: A Census-identified firm in which one establishment is matched to a foreigncountry parent firm, and another establishment is matched to a U.S. multinational firm.

1. Collapse the Census-identified firm employment based on the establishment-parent firm link by type of DCA link (Foreign vs U.S. Multinational)

2. Calculate the firm employment share of each establishment match

3. If one particular type of link yields an employment share above 0.75 , apply that link to all establishments within the firm.

4. If one particular type of link yields an employment share above 0.5 and total firm employment is below 10,000, then apply that link to all establishments within the firm.

\footnotetext{
${ }^{56}$ The multinational status of firms from the UBP directories are more straightforward.

${ }^{57}$ Some of these cases also apply to the UBP-BR bridge.
} 
5. All other cases require manual review.

Potential 3: A Census-identified firm in which one establishment is matched to a nonmultinational firm, and another establishment is matched to a foreign-country parent firm (or U.S. multinational firm).

Apply same steps as in Potential 2.

\section{B.2 Classifying Firm-Level Trade}

The firm-level data on imports available in the LFTTD does not contain information on the intended use of the goods ${ }^{58}$ Disentangling whether an imported product is used as an intermediate input for further processing - rather than for final sale in the U.S. - has important implications for the nature of FDI, and the role of imported goods in the transmission of shocks. Fortunately, the Census Bureau data contains other information that can be used to distinguish intermediate input imports from final goods imports. Creating lists of the principal products produced by firms in a given detailed industry in the United States should indicate the types of products that, when imported, should be classified as a "final" good - that is, intended for final sale without further processing. The products imported outside of this set, then, would be classified as intermediate goods 59 Such product-level production data exists as part of the "Products" trailer file of the Census of Manufacturers. As detailed in Pierce and Schott (2012) (see page 11), combining import, export, and production information at a product-level is useful for just such a purpose.

\section{B.2.1 Creating a NAICS-Based set of Final/Intermediate Products}

As part of the quinquennial Census of Manufacturers (CM), the Census Bureau surveys establishments on their total shipments broken down into a set of NAICS-based (6 digit) product categories. Each establishment is given a form particular to its industry with a list of pre-specified products, with additional space to record other product shipments not included in the form. The resulting product trailer file to the $\mathrm{CM}$ allows the researcher to understand the principal products produced at each manufacturing establishment during a census year.

There are several data issues that must be addressed before using the CM-Products file to infer information about the relative value of product-level shipments by a particular firm. First, the trailer file contains product-codes that are used to "balance" the aggregated product-level value of shipments with the total value of shipments reported on the base CM survey form. We drop these product codes from the dataset. Second, there are often codes that do not correspond to any official 7-digit product code identified by Census. (These are typically products that are self-identified by the firm but do not match any of the prespecified products identified for that industry by Census.) Rather than ignoring the value of shipments corresponding to these codes, we attempt to match at a more aggregated level. Specifically, we iteratively try to find a product code match at the 6,5 , and 4 digit product

\footnotetext{
${ }^{58}$ This is one advantage of the survey data on multinational firms available from the Bureau of Economic Analysis. There are, however, a number of critical disadvantages of this data source, as outlined in Flaaen (2013b).

${ }^{59}$ To be more precise, this set will include a combination of intermediate and capital goods.
} 
code level, and use the existing set of 7-digit matches as weights to allocate the product value among the 7-digit product codes encompassing the more aggregated level.

We now discuss how this file can be used to assemble a set of NAICS product codes that are the predominant output (final goods) for a given NAICS industry. Let $x_{p i j}$ denote the shipments of product $p$ by establishment $i$ in industry $j$ during a census year. Then the total output of product $p$ in industry $j$ can be written as:

$$
X_{p j}=\sum_{i=1}^{I_{j}} x_{p i j},
$$

where $I_{j}$ is the number of firms in industry $j$. Total output of industry $j$ is then:

$$
X_{j}=\sum_{p=1}^{P_{j}} X_{p j} .
$$

The share of industry output accounted for by a given product $p$ is therefore:

$$
S_{p j}=\frac{X_{p j}}{X_{j}}
$$

One might argue that the set of final goods products for a given industry should be defined as the set of products where $S_{p j}>0$. That is, a product is designated as a "final good" for that industry if any establishment recorded positive shipments of the product. The obvious disadvantage of employing such a zero threshold is that small degrees of within-industry heterogeneity will have oversized effects on the classification.

Acknowledging this concern, we set an exogenous threshold level $W$ such that any $p$ in a given $j$ with $S_{p j}>W$ is classified as a final good product for that industry. The upper portion of Table A2 documents the number of final goods products and the share of intermediate input imports based on several candidate threshold levels. The issues of a zero threshold are quite clear in the table; a small but positive threshold value (0.1) will have a large effect on the number of products designated as final goods. This shows indirectly that there are a large number of products produced by establishments in a given industry, but a much smaller number that comprise the bulk of total value.

There are several advantages to using the CM-Products file rather than using an inputoutput table ${ }^{60}$ First, within a given $\mathrm{CM}$ year, the classification can be done at the firm or establishment level rather than aggregating to a particular industry. This reflects the fact that the same imported product may be used as an input by one firm and sold to consumers as a final product by another. Second, the CM-Products file is one of the principal data inputs into making the input-output tables, and thus represents more finely detailed information. Related to this point, the input-output tables are produced with a significant delay - the most recent available for the U.S. is for year 2002. Third, the input-output tables for the

\footnotetext{
${ }^{60}$ Another option is to use the CM-Materials file, the flip side of the CM-Products file. Unfortunately, the CMMaterials file contains significantly more problematic product codes than the Products file, and so concording to the trade data is considerably more difficult.
} 
U.S. are based on BEA industry classifications, which imply an additional concordance (see below) to map into the NAICS-based industries present in the Census data.

We now turn to the procedure to map firm-level trade into intermediate and final goods using the industry-level product classifications calculated above.

\section{B.2.2 Mapping HS Trade Transactions to the Product Classification}

The LFTTD classifies products according to the U.S. Harmonized Codes (HS), which must be concorded to the NAICS-based product system in order to utilize the classification scheme from the CM-Products file. Thankfully, a recent concordance created by Pierce and Schott (2012) can be used to map the firm-HS codes present in the LFTTD data with the firmNAICS product codes present in the CM-Products data.

A challenge of this strategy is that the LFTTD exists at a firm-level, while the most natural construction of the industry-level classification scheme is by establishment. More concretely, for multi-unit, multi-industry firms, the LFTTD is unable to decompose an import shipment into the precise establishment-industry of its U.S. destination. 61 While recognizing the caution that should be used in this regard, we adopt the approach that is commonly used in such circumstances: the industry of the firm is defined as that industry encompassing the largest employment share.

Once the firm-level trade data is in the same product classification as the industry-level filter created from the CM-Products file, all that is left is to match the trade data with the filter by NAICS industry. Thus, letting $M_{i j}$ denote total imports from a firm $i$ (firm $i$ is classified as being in industry $j$ ), we can then categorize the firm's trade according to:

$$
\left.\begin{array}{l}
M_{i j}^{\mathrm{int}}=\sum_{p \notin P_{j}} M_{i p j} \\
M_{i j}^{\mathrm{fin}}=\sum_{p \in P_{j}} M_{i p j}
\end{array}\right\} \quad \text { where } \quad P_{j}=\left\{p \mid S_{p j} \geq W\right\} .
$$

The bottom section of Table A2 shows some summary statistics of the intermediate share of trade according to this classification system, by several values of the product-threshold $W$. There are at least two important takeaways from these numbers. First, the share of intermediates in total imports is roughly what is reported in the literature using IO Tables. Second, the share of total trade occupied by intermediate products is not particularly sensitive to the exogenous threshold level. While there is a small increase in the share when raising the threshold from 0 to 0.1 (about 3 percentage points), the number is essentially unchanged when raising it further to 0.2 .

\footnotetext{
${ }^{61}$ It is worth pointing out that the most obvious way that this would materialize is by vertical integration of the firm in its U.S. operations. Provided that the industry designation of the firm pertains to its most downstream operations, then this is would not serve to bias the firms' classification of imported goods, as the upstream products are not actually "final" goods for that firm.
} 


\section{B.3 Sample Selection}

\section{B.3.1 Constructing the Baseline Dataset}

This section will discuss the steps taken to construct the sample used in section 2.2.3.

Beginning with the raw files of the LFTTD export/import data, we drop any transactions with missing firm identifiers, and those pertaining to trade with U.S. territories. Next, we merge the LFTTD files with the HS-NAICS6 product concordance from Pierce and Schott (2012); if there is no corresponding NAICS6 code for a particular HS code, then we set NAICS6 equal to XXXXXX. We then aggregate up to the level of Firm-CountryMonth-NAICS6, and then create extracts according to three sets of destinations/sources: Japan, Non-Japan, and North America (Canada and Mexico). Then, assigning each firm to an LBD-based industry (see below), we run the NAICS-based trade codes through the intermediate/final goods filter discussed in Appendix B.2. The firms' monthly trade can then be split into intermediate and final goods components. We repeat this step for years 2009, 2010, and 2011.

Using the Longitudinal Business Database, we drop inactive, ghost/deleted establishments, and establishments that are not in-scope for the Economic Census. To create the sample of manufacturing firms in the U.S., we first create a firm industry code defined as the industry encompassing the largest share of firm employment. We then drop nonmanufacturing firms. Next, we merge the LBD for each year with the DCA-Bridge (see section B.1) containing multinational indicators. We then apply the rules specified above for clarifying disagreements with the DCA-based multinational indicators. After creating monthly copies of each firm, we merge by firm-month to the trade data. Missing information of trade data is altered to represent zeros. We repeat these steps for years 2009-2011, and then append the files together. Firms that do not exist in all three years are dropped from the sample.

\section{B.3.2 GIS Mapping of Earthquake Intensity Measures to Affiliate Locations}

As part of the Earthquake Hazards Program, the U.S. Geological Survey produces data and map products of the ground motion and shaking intensity following major earthquakes. The preferred measure to reflect the perceived shaking and damage distribution is the estimated "Modified Mercalli Intensity (MMI)" which is based on a relation of survey response and measured peak acceleration and velocity amplitudes. The USGS extends the raw data from geologic measurement stations and predicts values on a much finer grid using standard seismological inferences and interpolation methods. The result is a dense grid of MMI values covering the broad region affected by the seismic event. For more information on this methodology, see Wald et al. (2006).

To utilize this information, we take all Japanese addresses from the DCA/Uniworld directories that correspond to any U.S. operation via an ownership link. We geocode these addresses into latitude/longitude coordinates using the Google Geocoding API, and then compute the inverse distance-weighted mean of the relevant seismic intensity measure based on a $10 \mathrm{~km}$ radius surrounding a given establishment. The firm identifiers within the corporate directories allow us to create firm-specific measures (average and maximum values, 
by manufacturing/non-manufacturing), which can then be brought into the baseline Census dataset via the bridges discussed in appendix B.1. 
Table A1: Match Statistics: 2007-2011

\begin{tabular}{lccc}
\hline \hline & $\begin{array}{c}\text { \# of } \\
\text { Establishments }\end{array}$ & $\begin{array}{c}\text { Matched } \\
\text { to B.R. }\end{array}$ & $\begin{array}{c}\text { Percent } \\
\text { Matched }\end{array}$ \\
\hline Total & & & \\
2007 & 112,346 & 81,656 & 0.73 \\
2008 & 111,935 & 81,535 & 0.73 \\
2009 & 111,953 & 81,112 & 0.72 \\
2010 & 111,998 & 79,661 & 0.71 \\
2011 & 113,334 & 79,516 & 0.70 \\
U.S. Multinationals & & & \\
2007 & 22,500 & 16,396 & 0.73 \\
2008 & 23,090 & 16,910 & 0.73 \\
2009 & 22,076 & 16,085 & 0.73 \\
2010 & 21,667 & 15,785 & 0.73 \\
2011 & 21,721 & 15,557 & 0.72 \\
Foreign Multinationals & & & \\
2007 & 10,331 & 7,555 & 0.73 \\
2008 & 9,351 & 6,880 & 0.74 \\
2009 & 11,142 & 8,193 & 0.74 \\
2010 & 11,308 & 8,181 & 0.72 \\
2011 & 11,619 & 8,357 & 0.72 \\
& & & \\
\hline \hline
\end{tabular}

Table A2: Appendix Table Comparing the Results from Threshold Values W

\begin{tabular}{|c|c|c|c|}
\hline \multicolumn{4}{|c|}{$\begin{array}{lc}\text { Threshold Values } \\
\end{array}$} \\
\hline & $W=0$ & $W=0.1$ & $W=0.2$ \\
\hline \multicolumn{4}{|c|}{ Number of Final Good Products per Industry } \\
\hline Median & 19 & 1 & 1 \\
\hline Mean & 25 & 1.52 & 1.14 \\
\hline Min & 1 & 1 & 0 \\
\hline Max & 154 & 6 & 3 \\
\hline \multicolumn{4}{|c|}{ Implied Share of Intermediate Inputs } \\
\hline Imports & 60.9 & 63.90 & 63.97 \\
\hline Exports & 52.0 & 54.96 & 55.04 \\
\hline
\end{tabular}




\section{Appendix: Other Results}

\section{C.1 Alternate Specifications for Treatment Effects Regressions}

Our results from section 2.2.4 are based on a sample including all Japanese multinationals in manufacturing, and therefore uses a levels specification to allow for zeros in the firmmonth observations. Because larger firms exhibit greater absolute deviations from trend, this roughly amounts to weighting firms based on size, such that the results correspond to a representative firm based on the aggregate effect of the group.

To see this, and to explore how the levels specification influences our interpretation, we repeat the analysis on a subset of the firms for which we can view the percentage changes directly. Specifically, we drop any firms with zeros in any month for intermediate imports or N.A. exports during the sample, and then take logs and HP-filter each series to obtain percentage deviations from trend for each firm. ${ }^{62}$ The results of this exercise are shown in Panel A of Figure A1. We suppress standard errors for the sake of clarity; the drops are significant at the $95 \%$ level for between 2-4 months following the shock. If we rerun these regressions while also weighting according to the pre-shock size of firms, we obtain a picture that looks much closer to Figure 7, see Panel B of Figure A1.

These results indicate that the larger firms appear to be affected the most from this shock. This could be partly a result of our proxy being less effective for smaller firms that may not engage in consistent exports to North America.

\section{C.2 Effects on Employment and Payroll}

The Standard Statistical Establishment List (SSEL) contains quarterly employment and payroll information for all employers (with some small exceptions) in the U.S. economy. This list is held separately as a single-unit(SSEL-SU) and multi-unit (SSEL-MU) file. The Report of Organization Survey (ROS) asks firms to list the establishments which report under a particular EIN, and this information is then recorded to the firm identifier on the Multi-Unit File. To build a quarterly employment series at the firm-level, we link the EIN variables on the SU file with the firm-identifier linked with each EIN on the MU file. In principle, the four quarters of payroll listed on the SSEL is combined by Census to create an annual payroll figure for each establishment, which is the value recorded in the LBD. Similarly, the employment variable corresponding to the 1st quarter (week of March 12) from the SSEL is that used by the LBD.

Once we merge the SSEL-based data with quarterly employment and payroll to the LBD for a particular year, we conduct a series of reviews to ensure that the annual payroll (and 1st quarter employment) roughly align. Any establishments with disagreements between the SSEL-based payroll and LBD-based payroll such that the ratio was greater than 2 or less than 0.6 were dropped.

After these modifications were made, the remainder of the data construction was similar to that in section B.3. We merge multinational indicators from the DCA, drop nonmanufacturing firms, append the 2009, 2010, and 2011 files together, and keep only those

\footnotetext{
${ }^{62} \mathrm{We}$ re-weight the control group as described in section 2.2 .3
} 
firms that exist in each year. Using the same set of firms as a control group as specified in section 2.2.3, we run the following regression:

$$
\Delta \mathrm{emp}_{j, t}=\sum_{i=-3}^{3} \gamma_{i} E_{i}+\sum_{i=-3}^{3} \beta_{i} E_{i} D_{j, i}+u_{j, t}
$$

where $\Delta \operatorname{emp}_{j, t} \equiv \ln \left(\operatorname{emp}_{j, t} / \operatorname{emp}_{j, t-4}\right)$, where $\operatorname{emp}_{j, t}$ indicates employment at firm $j$ in quarter $t$. We also re-run the equation specified in equation A6 using payroll pay $y_{j, t}$ as the dependent variable (where $\Delta$ pay $_{j, t} \equiv \ln \left(\operatorname{pay}_{j, t} /\right.$ pay $\left._{j, t-4}\right)$. The qualitative results are shown in table A3.

\section{C.3 Effects on Unit Values (Prices) of Trade}

The LFTTD contains information on quantities as well as values for each trade transaction, recorded at a highly disaggregated product definition (HS 10 digit). This allows for the construction of unit values (prices) for each firm-product-month observation, which allows for an analysis of price movements surrounding the Tohoku event.

The majority of the data construction is identical to that in section B.3, however there are a number of modifications. First, we drop all transactions with missing or imputed quantities in the LFTTD, and then aggregate to the Firm-HS10-month frequency, separately for each type of trade transaction: 1) Related-Party imports from Japan; 2) Non Related-Party imports from Japan; 3) Related-Party exports to Canada/Mexico; and 4) Non Related-Party exports to Canada/Mexico. Next, we select only those firms identified as manufacturing in the LBD. We keep the related-party and arms-length transactions separate as one may expect these prices to behave differently following a shock. As above, we keep only manufacturing firms, append the annual files together, and then select only those firms identified as a multinational in either 2009, 2010, or 2011.

At the product level, there is little reason to suspect trends or seasonal variation over this short of a time period. Moreover, there is no concern here about accounting for zeros in the data. As such we take a firm $j$ 's imports (exports) of product $p$ in month $t$, and run the following specification in $\operatorname{logs}\left(\mathrm{m}_{p, j, t}=\log \left(\mathrm{M}_{p, j, t}\right)\right.$ :

$$
\mathrm{m}_{p, j, t}=\alpha_{p j}+\sum_{i=-19}^{9} \gamma_{i} E_{i}+\sum_{i=-19}^{9} \beta_{i} E_{i} D_{j, i}+u_{j, t}
$$

where $\alpha_{p j}$ are firmXproduct fixed-effects, $\gamma_{i}$ are monthly fixed effects (with the dummy variable $E_{i}^{\prime} s$ corresponding to each calendar month), and $u_{j, t}$ are random effects. The variables $D_{j, t}$ are dummy variables equal to one if the firm is owned by a Japanese parent company.

A qualitative version of the results is shown in Table A4.

\section{C.4 Ward's Automotive Data}

Ward's electronic databank offers a variety of data products for the global automotive industry at a monthly frequency. We obtain Japanese production (by model), North American 
production (by plant and model), U.S. inventory (by model), and North American sales (by model) all for the period January 2000 to December 2012. The inventory and sales data also contain the country of origin, so one can separate out these variables based on whether a particular model was imported vs domestically-produced. The series cover the universe of the assembly operations of finished cars and light trucks. Unfortunately, there is no information on input shipments.

For the plant-level analysis of production, the base sample consists of 167 plants active at some point during 2000-2012. We remove plants that were not continuously in operation during the period 2009-2012, and combine several plants that are recorded separately in the data, but are in effect the same plant. After these modifications, the sample reduces to 62 plants, 22 of which are owned by a Japanese parent. The average monthly production in the three months preceding the shock is 12,904 for Japanese plants, and 14,903 for Non-Japanese plants. The specification is identical to that in section 2.2.3.

$$
Q_{j t}=\alpha_{j}+\lambda_{j} t+\sum_{i=-4}^{9} \gamma_{i} E_{i}+\sum_{i=-4}^{9} \beta_{i} E_{i} D_{j, i}+u_{j, t}
$$

where here the variable $Q_{j, t}$ is auto production by plant $j$ in month $t$. Because these plants can be tracked with some confidence back in time, it is reasonable here to remove seasonality directly, rather than assume a shared seasonal component between the treated and control groups as in section 2.2.4. We use the X12-ARIMA model, provided by the National Bank of Belgium, and apply it to each series before correcting for trend. The results for the Japanese plants are mostly similar, as shown in table A5. 
Figure A1: Relative Inputs and Output (Proxy) of Japanese Firms (Reduced Sample) Logged, HP-Filtered

\section{A. No Size-Weighting}

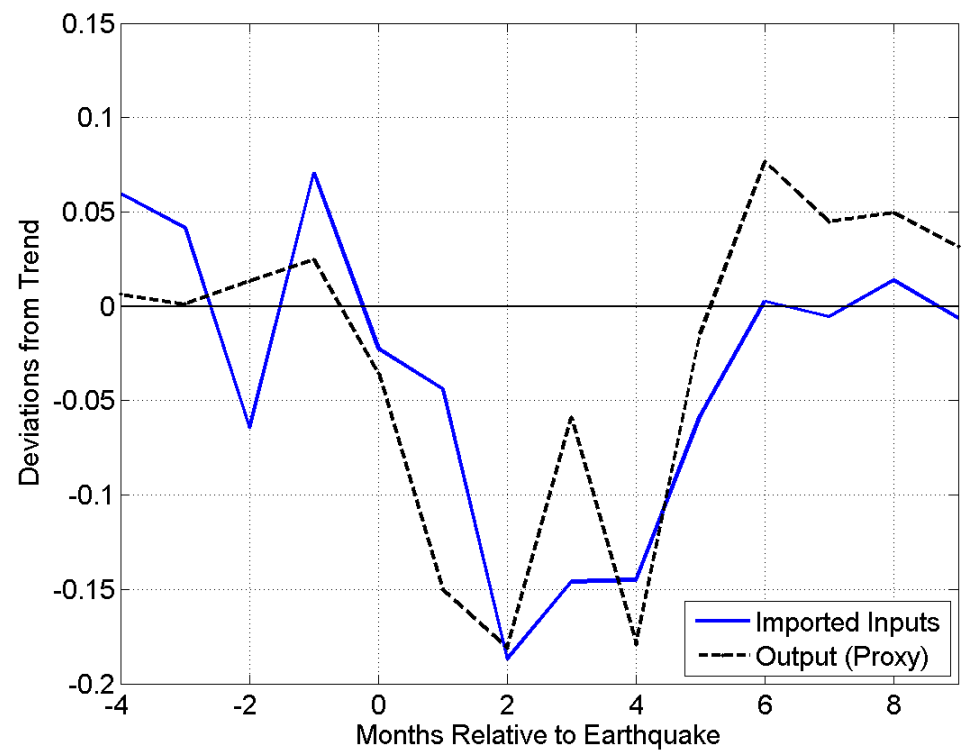

B. Size-Weighted

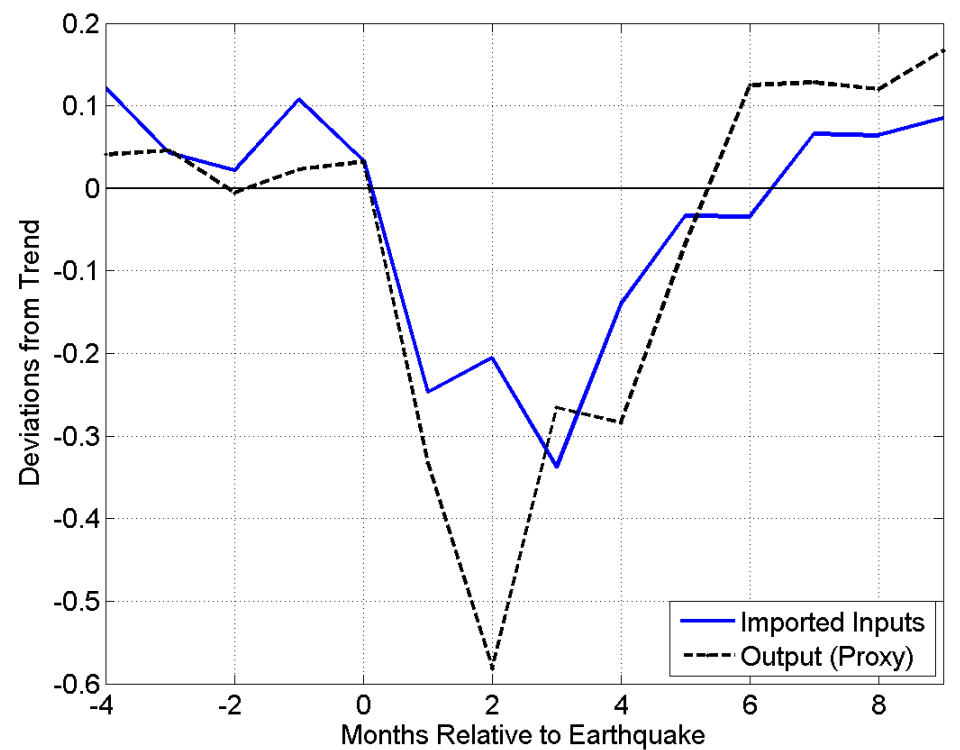

Source: LFTTD-DCA-UBP as explained in text.

These figures report the relative percentage deviations from trend of Japanese affiliates relative to a control group of other multinational firms. The values are coefficient estimates taken from an interaction of a Japanese-firm dummy with a monthly dummy - additional baseline monthly dummies remove seasonal effects. These results reflect a reduced sample with no firm-month zeros in imported inputs or N.A. exports. The data is logged, and HP-filtered using a monthly smoothing parameter. 
Table A3: Dynamic Treatment Effects: Quarterly Employment/Payroll Surrounding Tōhoku Event

\begin{tabular}{|c|c|c|}
\hline Independent Variables & $\begin{array}{c}\text { Log 4-Quarte } \\
\text { Employment } \\
\text { (1) }\end{array}$ & $\begin{array}{c}\text { Difference } \\
\text { Payroll } \\
(2)\end{array}$ \\
\hline $\mathrm{Q} 2 \_2010(\mathrm{t}=-3)$ & $\operatorname{pos}^{* * *}$ & $\operatorname{pos}^{* * *}$ \\
\hline $\mathrm{Q} 3 \_2010(\mathrm{t}=-2)$ & $\operatorname{pos}^{* * *}$ & $\operatorname{pos}^{* * *}$ \\
\hline $\mathrm{Q} 4 \_2010(\mathrm{t}=-1)$ & $\operatorname{pos}^{* * *}$ & $\operatorname{pos}^{* * *}$ \\
\hline $\mathrm{Q} 1 \_2011(\mathrm{t}=0)$ & $\operatorname{pos}^{* * *}$ & pos $* * *$ \\
\hline Q2 $2011(t=1)$ & $\operatorname{pos}^{* * *}$ & $\operatorname{pos}^{* * *}$ \\
\hline Q3_2011 $(\mathrm{t}=2)$ & $\operatorname{pos}^{* * *}$ & $\operatorname{pos}^{* * *}$ \\
\hline $\mathrm{Q} 4 \_2011(\mathrm{t}=3)$ & pos $* * *$ & $\operatorname{pos}^{* * *}$ \\
\hline $\mathrm{JPNxQ} 2 \_2010(\mathrm{t}=-3)$ & neg & neg \\
\hline JPNxQ3_2010 $(\mathrm{t}=-2)$ & neg & neg \\
\hline $\mathrm{JPNxQ} 4 \_2010(\mathrm{t}=-1)$ & neg & neg \\
\hline JPNxQ1_2011 $(\mathrm{t}=0)$ & neg & neg \\
\hline JPNxQ2_2011 $(\mathrm{t}=1)$ & neg & neg \\
\hline JPNxQ3_2011 $(\mathrm{t}=2)$ & neg & neg \\
\hline \multirow{2}{*}{$\begin{array}{l}\text { JPNxQ4_2011 ( } \mathrm{t}=3) \\
\text { constant }\end{array}$} & neg & pos \\
\hline & $\operatorname{neg}^{* * *}$ & $\operatorname{neg}^{* * *}$ \\
\hline & Yes & Yes \\
\hline \multirow{2}{*}{$\begin{array}{l}\text { Observations } \\
\text { R-squared }\end{array}$} & & \\
\hline & & \\
\hline
\end{tabular}

Source: SSEL and DCA as explained in the text.

Robust standard errors (clustered at the firmXProduct level) pertaining to each sign coefficient are indicated by: $* * * \mathrm{p}<0.01,{ }^{* *} \mathrm{p}<0.05, *$ $\mathrm{p}<0.1$.

This table reports qualitative features of firm employment and firm payroll in the quarters surrounding the Tōhoku earthquake and tsunami. The first set of coefficients correspond to quarter dummies, whereas the second set (JPNx) correspond to the interaction of a Japanese firm dummy with quarter dummies. See equation $\mathrm{A6}$ in the text. The dependent variable is the four-quarter log difference of employment (payroll). 
Table A4: Dynamic Treatment Effects: Unit Values of Trade Surrounding Tōhoku Event

\begin{tabular}{|c|c|c|c|c|}
\hline \multirow[b]{2}{*}{ Independent Variables } & \multicolumn{4}{|c|}{ "Log Unit-Value of: } \\
\hline & $\begin{array}{l}\text { JPN Imports: } \\
\text { Related Party } \\
\text { (1) }\end{array}$ & $\begin{array}{c}\text { JPN Imports: } \\
\text { Non-Related Party } \\
(2)\end{array}$ & $\begin{array}{l}\text { N.A. Exports } \\
\text { Related Party } \\
\qquad(3)\end{array}$ & $\begin{array}{c}\text { N.A. Exports } \\
\text { Non-Related Party } \\
(4)\end{array}$ \\
\hline Sep $2010(t=-6)$ & neg** & pos & pos* & pos \\
\hline Oct $2010(t=-5)$ & pos & neg & pos $* *$ & pos \\
\hline Nov $2010(t=-4)$ & pos & pos & $\operatorname{pos}^{* *}$ & pos \\
\hline $\operatorname{Dec} 2010(\mathrm{t}=-3)$ & pos & neg & pos & pos \\
\hline $\operatorname{Jan} 2011(\mathrm{t}=-2)$ & neg & pos & neg & pos \\
\hline Feb $2011(t=-1)$ & pos & neg & pos** & pos \\
\hline $\operatorname{Mar} 2011(\mathrm{t}=0)$ & neg & pos & pos & pos \\
\hline Apr $2011(t=1)$ & pos & pos & pos & pos \\
\hline May $2011(t=2)$ & neg & pos & neg & $\operatorname{pos}^{* *}$ \\
\hline Jun $2011(\mathrm{t}=3)$ & $\operatorname{pos}^{* *}$ & neg & $\operatorname{pos}^{* *}$ & neg \\
\hline Jul $2011(t=4)$ & neg & neg & pos & neg \\
\hline Aug $2011(t=5)$ & pos & pos & neg & pos \\
\hline Sep $2011(t=6)$ & pos & pos & pos & $\operatorname{pos}^{* *}$ \\
\hline Oct $2011(t=7)$ & neg & neg & pos & pos \\
\hline Nov $2011(t=8)$ & pos & neg & pos & neg \\
\hline Dec $2011(\mathrm{t}=9)$ & neg & pos & pos** & pos \\
\hline JPNxSep $2010(t=-6)$ & $\operatorname{pos}^{* *}$ & neg* & neg** & neg \\
\hline JPNxOct $2010(\mathrm{t}=-5)$ & neg* & pos & pos & pos \\
\hline JPNxNov $2010(\mathrm{t}=-4)$ & neg & pos & neg & neg \\
\hline JPNxDec $2010(\mathrm{t}=-3)$ & neg & neg* & pos & pos \\
\hline JPNxJan $2011(\mathrm{t}=-2)$ & pos & neg & neg & neg \\
\hline JPNxFeb $2011(\mathrm{t}=-1)$ & neg & pos & pos & $\operatorname{pos}^{* *}$ \\
\hline JPNxMar $2011(\mathrm{t}=0)$ & pos & pos & neg & neg \\
\hline JPNxApr $2011(t=1)$ & neg & pos & neg & neg \\
\hline JPNxMay $2011(t=2)$ & pos & neg & pos & neg \\
\hline JPNxJun $2011(\mathrm{t}=3)$ & neg & pos* & neg & neg \\
\hline JPNxJul $2011(t=4)$ & pos & neg & pos & neg \\
\hline JPNxAug $2011(t=5)$ & neg* & neg* & neg & pos \\
\hline JPNxSep $2011(t=6)$ & neg & neg & neg & neg \\
\hline JPNxOct $2011(\mathrm{t}=7)$ & pos & neg & neg & neg \\
\hline JPNxNov $2011(\mathrm{t}=8)$ & neg & neg & neg & pos \\
\hline JPNxDec $2011(\mathrm{t}=9)$ & neg & neg & pos & neg \\
\hline constant & pos & neg & neg & neg \\
\hline $\begin{array}{l}\text { FirmXProduct Fixed Effect } \\
\text { Observations } \\
\text { R-Squared }\end{array}$ & Yes & Yes & Yes & Yes \\
\hline
\end{tabular}

Source: LFTTD, DCA, and UBP as explained in the text.

Robust standard errors (clustered at the firmXProduct level) pertaining to each sign coefficient are indicated by: $* * *$ $\mathrm{p}<0.01,{ }^{* *} \mathrm{p}<0.05,{ }^{*} \mathrm{p}<0.1$.

This table reports qualitative features of the unit values of trade surrounding the 2011 Tōhoku earthquake and tsunami. The first set of coefficients correspond to monthly dummies, whereas the second set (JPNx) correspond to the interaction of a Japanese firm dummy with monthly dummies. See equation A7 in the text. 
Figure A2: Automotive Production, Inventory, Sales by Firm Type, Distributed Lag Model

N.A. Production

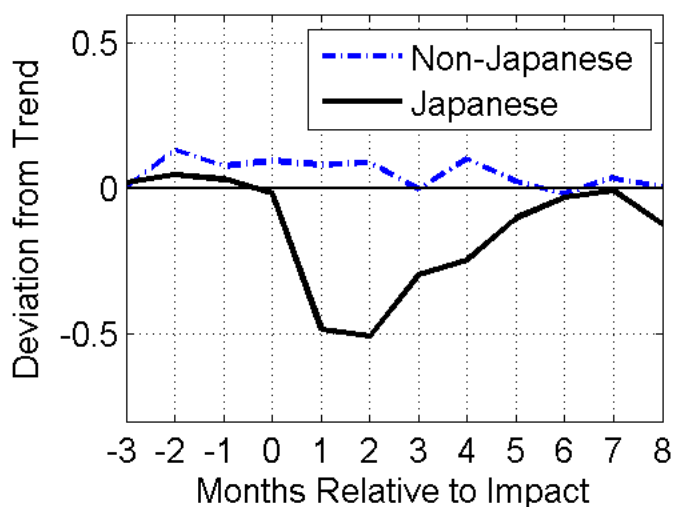

U.S. Inventory

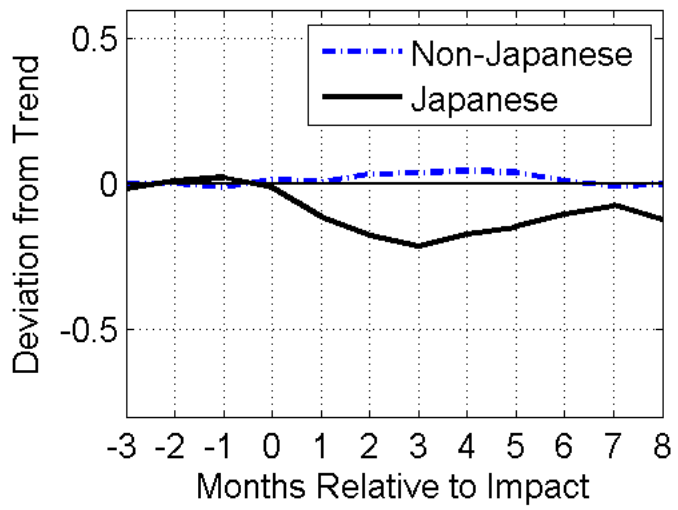

U.S. Sales

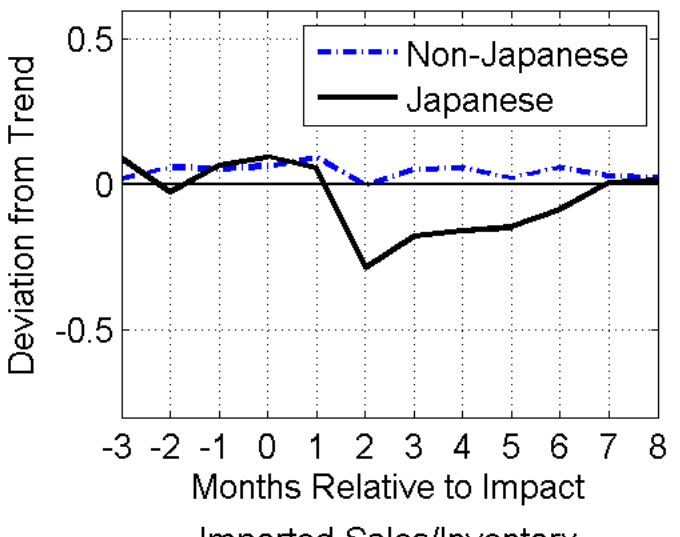

Imported Sales/Inventory

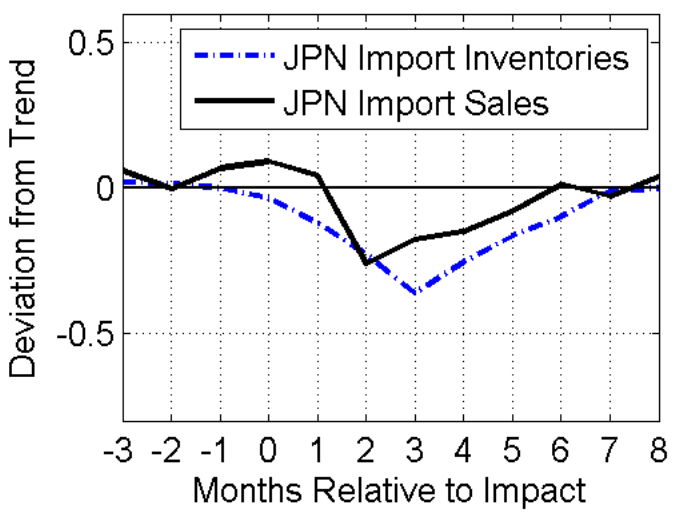

Source: Ward's Automotive Database

This figure reports North American production, and U.S. sales and inventory data according to firm type: Japanese and non-Japanese firms. The values are coefficient estimates taken from a distributed lag model, exploiting time-series variation only. The underlying series have been seasonally adjusted, logged, and HPFiltered Standard errors are suppressed in the interests of clarity. The Japanese automakers are Honda, Mazda, Mitsubishi, Nissan, Toyota, and Subaru. 
Table A5: Dynamic Treatment Effects: N.A. Automotive Production

\begin{tabular}{|c|c|c|c|c|c|}
\hline VARIABLES & $\begin{array}{c}(1) \\
\text { Prod }\end{array}$ & $\begin{array}{c}(2) \\
\text { Prod }\end{array}$ & VARIABLES (cont'd) & $\begin{array}{c}(1) \\
\text { Prod (cont'd) }\end{array}$ & $\begin{array}{c}(2) \\
\text { Prod (cont'd) }\end{array}$ \\
\hline Nov $2010(t=-4)$ & $\begin{array}{l}91.06 \\
(649.9)\end{array}$ & $\begin{array}{l}17.78 \\
(608.8)\end{array}$ & JPN x Nov $2010(t=-4)$ & $\begin{array}{l}-195.8 \\
(841.9)\end{array}$ & $\begin{array}{l}-341.7 \\
(799.2)\end{array}$ \\
\hline Dec $2010(\mathrm{t}=-3)$ & $\begin{array}{c}-1,973^{* * *} \\
(467.5)\end{array}$ & $\begin{array}{c}310.3 \\
(497.5)\end{array}$ & JPN x Dec $2010(t=-3)$ & $\begin{array}{l}-385.0 \\
(736.5)\end{array}$ & $\begin{array}{l}-408.3 \\
(706.4)\end{array}$ \\
\hline Jan $2011(t=-2)$ & $\begin{array}{l}-611.5 \\
(637.3)\end{array}$ & $\begin{array}{l}1,083^{*} \\
(618.7)\end{array}$ & JPN x Jan $2011(t=-2)$ & $\begin{array}{l}781.0 \\
(792.1)\end{array}$ & $\begin{array}{l}-1,092 \\
(804.6)\end{array}$ \\
\hline Feb $2011(t=-1)$ & $\begin{array}{l}694.9^{*} \\
(401.9)\end{array}$ & $\begin{array}{l}756.3^{*} \\
(394.7)\end{array}$ & JPN x Feb $2011(t=-1)$ & $\begin{array}{l}-1,142 \\
(696.2)\end{array}$ & $\begin{array}{l}-1,210^{*} \\
(666.8)\end{array}$ \\
\hline Mar $2011(\mathrm{t}=0)$ & $\begin{array}{c}4,356^{* * *} \\
(524.9)\end{array}$ & $\begin{array}{c}1,483^{* * *} \\
(389.1)\end{array}$ & JPN x Mar $2011(t=0)$ & $\begin{array}{c}-3,515^{* * *} \\
(812.0)\end{array}$ & $\begin{array}{c}-2,592^{* * *} \\
(842.7)\end{array}$ \\
\hline Apr $2011(t=1)$ & $\begin{array}{l}-216.2 \\
(707.7)\end{array}$ & $\begin{array}{l}305.5 \\
(620.4)\end{array}$ & JPN x Apr $2011(t=1)$ & $\begin{array}{c}-6,239^{* * *} \\
(1,303)\end{array}$ & $\begin{array}{c}-6,099^{* * *} \\
(1,282)\end{array}$ \\
\hline May $2011(\mathrm{t}=2)$ & $\begin{array}{c}1,584^{* * *} \\
(525.4)\end{array}$ & $\begin{array}{l}799.1 \\
(511.3)\end{array}$ & JPN x May $2011(t=2)$ & $\begin{array}{c}-7,244^{* * *} \\
(1,651)\end{array}$ & $\begin{array}{c}-6,625^{* * *} \\
(1,740)\end{array}$ \\
\hline Jun $2011(t=3)$ & $\begin{array}{l}1,366^{* *} \\
(623.6)\end{array}$ & $\begin{array}{l}-499.3 \\
(594.9)\end{array}$ & JPN x Jun $2011(t=3)$ & $\begin{array}{c}-4,564^{* * *} \\
(1,248)\end{array}$ & $\begin{array}{c}-3,423^{* *} \\
(1,320)\end{array}$ \\
\hline Jul $2011(t=4)$ & $\begin{array}{c}-4,512^{* * *} \\
(878.4)\end{array}$ & $\begin{array}{l}123.3 \\
(606.2)\end{array}$ & JPN x Jul $2011(\mathrm{t}=4)$ & $\begin{array}{l}-2,143 \\
(1,430)\end{array}$ & $\begin{array}{c}-3,723^{* * *} \\
(1,045)\end{array}$ \\
\hline Aug $2011(t=5)$ & $\begin{array}{l}685.6 \\
(744.0)\end{array}$ & $\begin{array}{c}-1,323^{* *} \\
(648.1)\end{array}$ & JPN x Aug $2011(\mathrm{t}=5)$ & $\begin{array}{l}-1,275 \\
(970.8)\end{array}$ & $\begin{array}{l}-1,108 \\
(1,012)\end{array}$ \\
\hline Sep $2011(t=6)$ & $\begin{array}{l}-836.5 \\
(663.7)\end{array}$ & $\begin{array}{c}-1,895^{* * *} \\
(641.5)\end{array}$ & JPN x Sep $2011(t=6)$ & $\begin{array}{l}-359.4 \\
(930.7)\end{array}$ & $\begin{array}{c}40.37 \\
(959.8)\end{array}$ \\
\hline Oct $2011(\mathrm{t}=7)$ & $\begin{array}{l}-338.0 \\
(662.3)\end{array}$ & $\begin{array}{c}-1,434^{* *} \\
(632.4)\end{array}$ & JPN x Oct $2011(t=7)$ & $\begin{array}{c}93.27 \\
(885.6)\end{array}$ & $\begin{array}{l}-265.4 \\
(785.8)\end{array}$ \\
\hline Nov $2011(t=8)$ & $\begin{array}{c}-1,393^{* *} \\
(582.8)\end{array}$ & $\begin{array}{c}-1,443^{* *} \\
(601.2)\end{array}$ & JPN x Nov $2011(t=8)$ & $\begin{array}{l}-1,318 \\
(1,159)\end{array}$ & $\begin{array}{l}-2,059^{*} \\
(1,183)\end{array}$ \\
\hline Dec $2011(t=9)$ & $\begin{array}{c}-4,511^{* * *} \\
(774.4)\end{array}$ & $\begin{array}{c}-1,619^{* *} \\
(655.5)\end{array}$ & JPN x Dec $2011(\mathrm{t}=9)$ & $\begin{array}{c}759.1 \\
(1,105)\end{array}$ & $\begin{array}{c}24.95 \\
(803.9)\end{array}$ \\
\hline Constant & & & & $\begin{array}{c}-1,535^{* * * *} \\
(89.30)\end{array}$ & $\begin{array}{c}-1,683^{* * *} \\
(91.95)\end{array}$ \\
\hline \multirow{3}{*}{\multicolumn{4}{|c|}{$\begin{array}{l}\text { Plant Fixed Effects } \\
\text { Remove Plant-Specific Pre-Shock Trend } \\
\text { Remove Seasonal Component }\end{array}$}} & Yes & Yes \\
\hline & & & & Yes & Yes \\
\hline & & & & No & Yes \\
\hline \multirow{2}{*}{\multicolumn{4}{|c|}{$\begin{array}{l}\text { Observations } \\
\text { R-squared }\end{array}$}} & 2,976 & 2,976 \\
\hline & & & & 0.260 & 0.272 \\
\hline
\end{tabular}

Source: Ward's Automotive Yearbook

Robust standard errors (clustered at the plant level) in parentheses. ${ }^{* * *} \mathrm{p}<0.01,{ }^{* *} \mathrm{p}<0.05,{ }^{*} \mathrm{p}<0.1$. 